\title{
Crustal velocity field of western Europe from permanent GPS array solutions, 1996-2001
}

\author{
J.-M. Nocquet ${ }^{1}$ and E. Calais ${ }^{2}$ \\ ${ }^{1}$ Institut Géographique National, Laboratoire de Recherche en Géodésie, Marne-la-Vallée, France.E-mail: nocquet@ensg.ign.fr \\ ${ }^{2}$ Purdue University, Department of Earth and Atmospheric Sciences, West Lafayette, IN 47907-2051, USA
}

Accepted 2003 January 24. Received 2002 December 6; in original form 2002 April 1

\begin{abstract}
SUMMAR Y
We derive a new geodetic velocity field for western Europe and the Western Mediterranean by rigorously combining (1) a selection of 36 ITRF2000 sites, (2) a solution from a subset of sites of the European Permanent GPS Network (EUREF-EPN), (3) a solution of the French national geodetic permanent GPS network (RGP) and (4) a solution of a permanent GPS network in the western Alps (REGAL). The resulting velocity field describes horizontal crustal motion at 64 sites in Western Europe with an accuracy of the order of $1 \mathrm{~mm} \mathrm{yr}^{-1}$ or better. Its analysis shows that Central Europe (defined as east of the Rhine Graben and north of the Alps and the Carpathians) behaves rigidly at a $0.4 \mathrm{~mm} \mathrm{yr}^{-1}$ level and defines a stable Europe reference frame. In that reference frame, we find no significant motion at sites located west of the Rhine graben and on the Iberian peninsula, which sets an upper bound of $0.6 \mathrm{~mm} \mathrm{yr}^{-1}$ on horizontal motion across the Rhine graben and the Pyrenees. We find that the current strain pattern in the western Alps combines $\mathrm{E}-\mathrm{W}$ extension and right-lateral shear. We confirm a counterclockwise rotation of the Adriatic microplate, which appears to control the strain pattern along its boundaries in the Friuli area, the Alps and the Apennines. Our results also suggest that the Africa-Eurasia plate motion in the Western Mediterranean may be 40-50 per cent slower that the NUVEL1A plate motion model and rotated $20^{\circ}-30^{\circ}$ counterclockwise.
\end{abstract}

Key words: continental deformation, geodesy, GPS, interplate deformation, plate motions.

\section{INTRODUCTION}

The Western Mediterranean domain, surrounded by the Alpine ranges is part of the broad plate boundary zone accommodating the relative motion between the African and the Eurasian plate. According to the NUVEL-1A global kinematic model (DeMets et al. $1990,1994)$, both plates are converging in a NW-SE direction at a rate of $3 \mathrm{~mm} \mathrm{yr}^{-1}$ at the longitude of the Gibraltar strait, increasing eastward to $8 \mathrm{~mm} \mathrm{yr}^{-1}$ near Sicily. The current Africa-Eurasia kinematics remains, however, to be confirmed or refined by direct geodetic measurements, still lacking on the African Plate. Deformation within the plate boundary zone is mainly concentrated in the Alpine ranges (Betics, Atlas and Maghrebides, Apennines, Dinarides, Alps, see Fig. 1). However, if compression and shortening are clearly expressed in the Maghrebides (e.g. Morel \& Meghraoui 1996) and the Dinarides (Anderson \& Jackson 1987), seismotectonic and geodetic studies (e.g. Anderson \& Jackson 1987; Hunstad \& England 1999; D'Agostino et al. 2001) clearly show that NE-SW extension dominates the strain regime along the Apennines. In the Alps, the deformation regime still remains to be clearly established. Seismotectonic data and preliminary geodetic results indicate that it includes a significant part of the strike-slip motion and extension in its western part (Eva \& Solarino 1998; Sue et al. 1999; Calais et al. 2002; Vigny et al. 2002). The relationship between these active extensional features within the Africa-Eurasia plate boundary zone and the Africa-Eurasia convergence remains an open question (D'Agostino \& McKenzie 1999; Mantovani et al. 2000). Finally, several relatively aseismic domains embedded in the plate boundary zone might be interpreted either as rigid blocks or microplates kinematically independent from the African and Eurasian plates (Corso-Sardinian block, Adriatic and Iberian microplates) or as rigid undeformed sedimentary basins (Provençal and Algerian basins, Pannonian basin).

North of the Western Mediterranean, Western Europe is a continental domain, part of the Eurasian plate, where significant active deformation is restricted to a few structures such as the Rhine graben (Fig. 1). However, post-glacial isostatic adjustment (GIA) alone is responsible for $1-2 \mathrm{~mm} \mathrm{yr}^{-1}$ of horizontal motion in Fennoscandia (Milne et al. 2001) and its influence in Western Europe south of Fennoscandia remains to be directly assessed (Marotta \& Sabadini 2002).

The determination of an accurate continent-scale geodetic velocity field is therefore essential to understanding inter- and intraplate deformation, investigating the processes that drive continental deformation and controlling the associated seismicity. If precision levels of the order of 2-3 $\mathrm{mm} \mathrm{yr}^{-1}$ (horizontally) are routinely achieved 


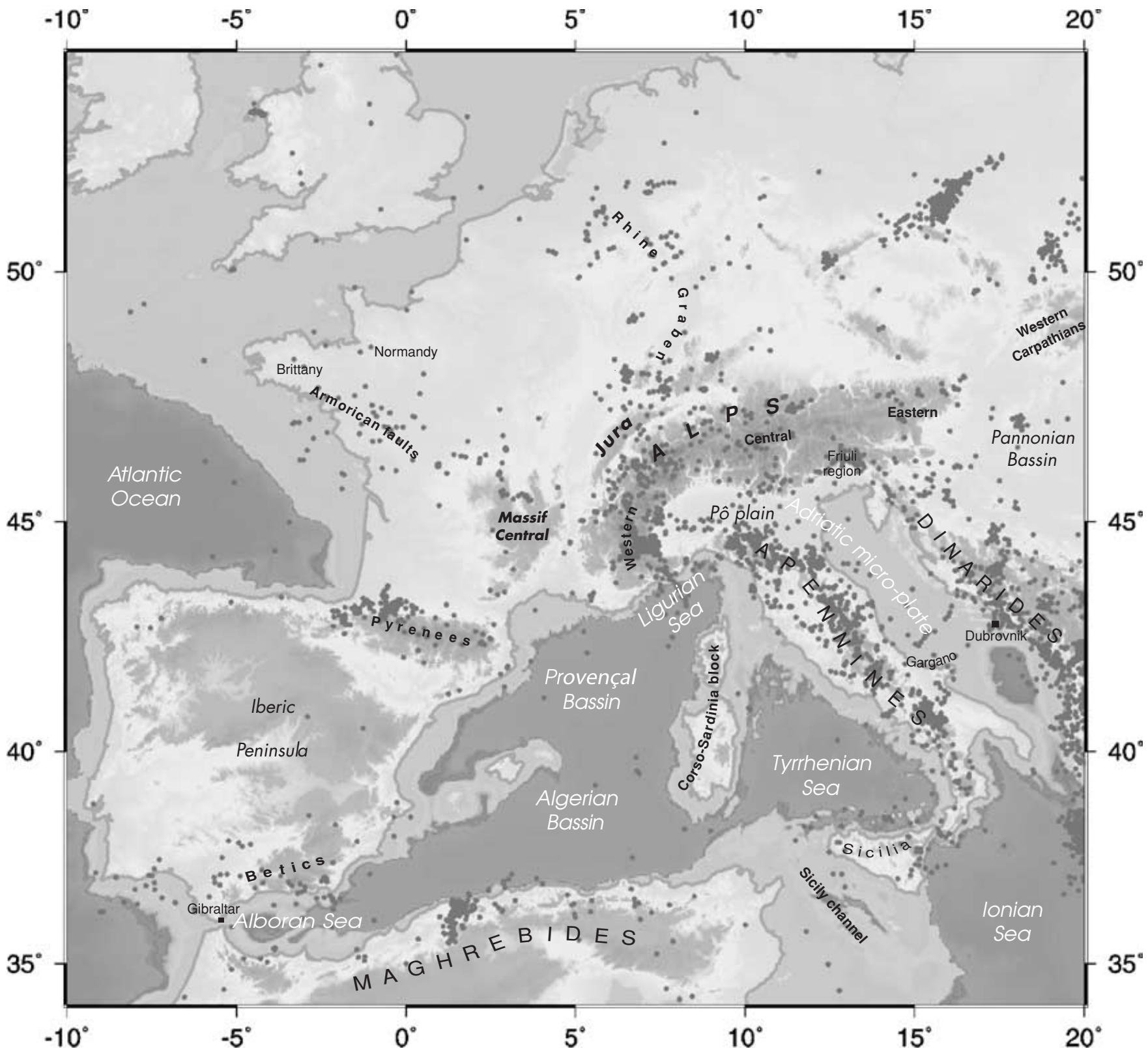

Figure 1. Major tectonic regions of Western Europe and Western Mediterranean; epicentre locations are taken from the NEIC catalogue (http:// neic.usgs.gov/neis/epic/epic.html) for the span 1980-2000.

by geodetic measurements, the determination of a dense and consistent velocity field at a continental scale, accurate at a submillimetre per year level, still remains a challenge. In this study, we present the realization of a velocity field for Western Europe consisting of 64 sites determined at a $1 \mathrm{~mm} \mathrm{yr}^{-1}$ accuracy level, based on the combination of three permanent GPS network results with the latest release of the International Terrestrial Reference Frame (ITRF2000). We describe the combination methodology, with a particular emphasis on constraint handling issues in permanent GPS network solutions. The analysis of the velocity field builds on earlier results by Nocquet et al. (2001) based on a statistical analysis of a selection of 29 sites from the ITRF97 velocity field. The present study goes significantly further because the new velocity field presented here includes the rigorous combination of several independent geodetic solutions. The resulting velocity field now includes 64 sites, significantly longer data span at all sites, and is based on ITRF2000, a version of the terrestrial reference frame much improved over ITRF97. We analyse the velocity field using the methodology of Nocquet et al. (2001), compare it with previous results and propose a preliminary interpretation in terms of plate motion and active deformation in Western Europe and the Western Mediterranean.

\section{INPUT DATA}

\subsection{ITRF2000}

The ITRF2000 is the current realization of the International Terrestrial Reference System (ITRS) published by the International Earth Rotation Service (IERS). It consists of a set of station positions and velocities at about 500 globally distributed control sites and their associated variance-covariance matrix (Altamimi et al. 2002). The 
ITRF is achieved by a combination of global geodetic solutions. For the 2000 realization of ITRS, three VLBI, one LLR, seven SLR, six GPS, two DORIS and two multitechnique solutions were selected as input data. In addition, nine regional GPS solutions were included in the combination for regional densification purposes. For the first time, only solutions with loose, removable or minimal a priori constraints on site positions and velocities were included. VLBI, LLR and SLR solutions benefit from $\sim 20$ years of measurements. GPS and DORIS solutions include $2-10$ years of continuous recording. The weighted rms of velocities in the combination is $<1 \mathrm{~mm} \mathrm{yr}^{-1}$ for VLBI solutions, $1-5 \mathrm{~mm} \mathrm{yr}^{-1}$ for SLR solutions, $1-2 \mathrm{~mm} \mathrm{yr}^{-1}$ for GPS solutions, and $4-5 \mathrm{~mm} \mathrm{yr}^{-1}$ for DORIS solutions.

ITRF2000 includes longer data spans, more homogeneous contributions from additional data analysis centres, and an improved combination strategy (Altamimi et al. 2002). ITRF2000 is therefore significantly more accurate than ITRF97. In addition, its associated variance-covariance matrix is a better estimate of its actual accuracy.

Since our goal is to detect crustal motions at the $1 \mathrm{~mm} \mathrm{yr}^{-1}$ level, we selected ITRF2000 sites that satisfy strict quality criteria (Nocquet et al. 2001): (1) standard deviation of horizontal velocity $<1 \mathrm{~mm} \mathrm{yr}^{-1}$; (2) weighted rms of horizontal velocity residuals $<2 \mathrm{~mm} \mathrm{yr}^{-1}$ in the combination; (3) velocity obtained from at least three different individual solutions; (4) agreement between at least three individual solutions and the ITRF2000 final value better than $1.5 \mathrm{~mm} \mathrm{yr}^{-1}$; and (5) a minimum of 4 years of continuous GPS data in individual solutions for sites not collocated with other techniques. The 36 selected sites are listed in Table 1 with their characteristics. MEDI (Medicina), with a wrms of $3.3 \mathrm{~mm} \mathrm{yr}^{-1}$, does not fulfil criterion (3), but was nevertheless included in this study because of its geodetic and geophysical interest (multitechnique geodetic site and active deformation in the Apennines).

\subsection{Regional networks}

\subsubsection{The EUREF Permanent Network}

The EUREF Permanent GPS Network (EPN, http://www. epncb.oma.be) was set up in 1995 in order to improve the realization of the European reference frame, that was until then done by GPS campaigns. The EPN consists of a selection of $\sim 145$ permanent stations distributed in Western Europe. The processing of the EPN is distributed between 13 analysis centres, ensuring that each site is processed by at least three different centres. The EUREF final position solution is derived weekly from a combination of the solutions provided by these analysis centres. In this work, we used 45 EPN sites located in Central and Western Europe with at least 2 years of continuous data. 24 of them are also included in our ITRF2000 site selection (Table 1). Our input data consists of weekly SINEX files from the EUREF-EPN for these 45 sites, spanning the period 1996 July to 2001 July 8 .

\subsubsection{The RGP Permanent Network solution}

The RGP (Réseau GPS Permanent, French permanent GPS network) started operating in 1998. It currently consists of 20 stations operated by several agencies and universities, with data archived at the Institut Géographique National (IGN/LAREG). The IGN/LAREG processes this network together with 20 other permanent GPS stations of the EPN (Table 2). A subset extracted from the weekly IGN/LAREG solution contributes to the EUREF-EPN solution. In the solution used here, 18 of the stations included in the IGN/LAREG solution are EPN stations and are therefore processed by at least two other EUREF analysis centres. The IGN/LAREG weekly position solution is produced using the Bernese 4.2 software (Beutler et al. 2001), following the standard strategy defined in the EUREF recommendations (ftp://ftp.epncb.oma.be/pub/center/analysis/IGN.LAC). Final IGS orbits and IERS Earth Orientation are fixed in the processing, while station coordinates are left unconstrained. Daily normal equations are then stacked to form a weekly solution. Weekly repeatabilities are 2.2 and $4.1 \mathrm{~mm}$ in the horizontal and vertical components, respectively. A previous RGP solution, with fewer sites and a shorter data time span included in the ITRF2000 showed a wrms of $0.5 \mathrm{~mm} \mathrm{yr}^{-1}$ for horizontal velocities. Our input data consists of weekly SINEX files for these 40 sites, spanning the period 1998 January 1 to 2001 August 28.

\subsubsection{The REGAL permanent network solution}

The REGAL network is a permanent GPS array covering the western Alps and their surroundings, dedicated to crustal deformation monitoring (Calais et al. 2000). The REGAL network started operating in 1997 and currently consists of 19 stations, four of them contributing to the RGP. We processed the REGAL network using the GAMIT software version 10.05 (King \& Bock 2001), including four additional RGP stations and 25 EUREF-EPN stations. We solve for station coordinates, satellite state vectors, seven tropospheric delay parameters per site and day, and phase ambiguities using double-differenced GPS phase measurements, with IGS final orbits and IERS earth orientation parameters relaxed. We obtain long-term repeatabilities of the order of $2-3 \mathrm{~mm}$ for the horizontal components, and $\sim 8 \mathrm{~mm}$ for the vertical component. For this study, we selected REGAL sites that have been operating continuously for at least $2 \mathrm{yr}$ (Table 3). Our input data therefore consists of daily SINEX files for 53 sites, spanning the period 1996 January 1 to 2001 July 20.

\subsection{Realization of individual solutions}

\subsubsection{EUREF-EPN and RGP solutions}

In order to simultaneously derive time-series and velocities from the weekly solutions used in this study (EUREF and RGP), we use the general concepts developed for the reference frame definition and the coordinates/velocities solutions combination (e.g. Brockmann 1997; Davies \& Blewitt 2000; Altamimi et al. 2002). Sillard \& Boucher (2001) recently pointed out the influence of reference frame constraints in geodetics results and combination. They proposed a strategy using 'minimum constraints' in order to handle the reference frame definition properly in geodetic solutions. Hereafter, we follow their approach. We start by removing the constraints that were added in individual solutions for reference frame definition. For instance, EUREF weekly combined solutions are provided with a priori constraints of $10^{-4} \mathrm{~m}$ on the position components of a subset of 14 ITRF97 welldetermined stations (BOR1, GRAZ, KOSG, MATE, ONSA, POTS, REYK, WTZR, ZWEN, VILL, GRAS, NYA1, TRO1 and THU1, see http://www.epncb.oma.be/products.html). Such tight constraints can significantly modify the original relative position and the derived velocities. We therefore remove these constraints using the a priori variance-covariance matrix, following the relation

$\Sigma_{\text {uncons }}^{-1}=\Sigma_{\text {cons }}^{-1}-\Sigma_{\text {apriori }}^{-1}$, 
Table 1. Selected ITRF2000 sites.

\begin{tabular}{|c|c|c|c|c|c|c|c|c|c|}
\hline \multirow[t]{2}{*}{ Site } & \multirow[t]{2}{*}{ Country } & \multicolumn{5}{|c|}{ Number of solutions } & \multirow[t]{2}{*}{ wrms } & \multirow[t]{2}{*}{$\sigma_{V_{e}}$} & \multirow[t]{2}{*}{$\sigma_{V_{n}}$} \\
\hline & & $\mathrm{R}$ & $\mathrm{L}$ & $\mathrm{P}$ & $\mathrm{D}$ & M & & & \\
\hline GRAS & France & 3 & 7 & 8 & & & 0.3 & 0.1 & 0.2 \\
\hline TOUL & France & & 2 & 7 & 2 & 2 & 1.0 & 0.3 & 0.3 \\
\hline ONSA & Sweden & 3 & & 7 & & & 0.2 & 0.1 & 0.1 \\
\hline METS & Finland & 2 & 7 & 7 & 2 & 5 & 0.6 & 0.2 & 0.2 \\
\hline GRAZ & Austria & & 7 & 8 & & 2 & 0.5 & 0.1 & 0.2 \\
\hline SOFI & Bulgaria & & 1 & 4 & & 2 & 1.5 & 0.8 & 0.1 \\
\hline PENC & Hungary & & & 4 & & & 0.9 & 0.3 & 0.4 \\
\hline GOPE & Czech Rep. & & & 5 & & & 0.3 & 0.2 & 0.2 \\
\hline JOZE & Poland & & & 3 & & & 0.3 & 0.2 & 0.2 \\
\hline BOR1 & Poland & & 7 & 6 & 0 & 2 & 0.5 & 0.4 & 0.5 \\
\hline BOGO & Poland & & & 3 & & & 0.3 & 0.2 & 0.2 \\
\hline LAMA & Poland & & & 6 & & & 0.3 & 0.6 & 0.8 \\
\hline RIGA & Latvia & & 7 & 1 & & 3 & 1.6 & 0.6 & 0.8 \\
\hline MDVO & Russia & & & 4 & & 1 & 0.3 & 0.3 & 0.3 \\
\hline ZWEN & Russia & & & 7 & & & 0.3 & 0.3 & 0.2 \\
\hline 7561 & Ukraine & 3 & 7 & & & 5 & 1.1 & 0.4 & 0.5 \\
\hline GLSV & Ukraine & & & 4 & & & 0.5 & 0.7 & 0.8 \\
\hline MEDI & Italy & 3 & 1 & 6 & & & 3.3 & 0.1 & 0.2 \\
\hline NOTO & Italy & 3 & 3 & 6 & & 2 & 1.2 & 0.1 & 0.2 \\
\hline CAGL & Italy & & 6 & 5 & & 4 & 2.1 & 0.3 & 0.3 \\
\hline MATE & Italy & 3 & 7 & 8 & & 3 & 0.3 & 0.2 & 0.2 \\
\hline UPAD & Italy & & & 8 & & & 1.1 & 0.3 & 0.3 \\
\hline BRUS & Belgium & & & 6 & & & 0.3 & 0.1 & 0.2 \\
\hline HERS & United Kingdom & & 7 & 8 & & 2 & 1.1 & 0.1 & 0.2 \\
\hline SFER & Spain & & 5 & 5 & & 2 & 1.2 & 0.5 & 0.5 \\
\hline VILL & Spain & & & 8 & & & 0.3 & 0.2 & 0.2 \\
\hline MADR & Spain & 3 & & 4 & & & 0.5 & 0.2 & 0.2 \\
\hline EBRE & Spain & & & 6 & & & 1.0 & 0.3 & 0.3 \\
\hline KOSG & Netherlands & & 5 & 6 & & 1 & 0.3 & 0.1 & 0.2 \\
\hline WSRT & Netherlands & & & 6 & & & 0.6 & 0.3 & 0.4 \\
\hline CASC & Portugal & & & 4 & & & 1.6 & 0.2 & 0.2 \\
\hline ZIMM & Switzerland & & 7 & 7 & & 3 & 0.4 & 0.1 & 0.2 \\
\hline POTS & Germany & & 7 & 7 & & 3 & 0.3 & 0.1 & 0.1 \\
\hline WTZR & Germany & 3 & 5 & 12 & & 2 & 0.4 & 0.1 & 0.1 \\
\hline OBER & Germany & & & 7 & & & 0.5 & 0.3 & 0.3 \\
\hline 7203 & Germany & & & 3 & & & 0.1 & 0.2 & 0.2 \\
\hline
\end{tabular}

$\mathrm{R}=\mathrm{VLBI}, \mathrm{L}=\mathrm{SLR}, \mathrm{P}=\mathrm{GPS}, \mathrm{D}=$ DORIS, $\mathrm{M}=$ Multitechnique solution; wrms is the weighted rms of the horizontal velocity residuals in the ITRF2000 combination; $\sigma_{V_{e}}$ and $\sigma_{V_{n}}$ are the standard deviations of the velocity (east and north component, respectively); values are $\mathrm{mm} \mathrm{yr}^{-1}$.

Table 2. Number of sites per solution and number of common sites shared by pair of solutions.

\begin{tabular}{lcccc}
\hline & EUREF-IG & ITRF2000 & RGP & REGAL \\
\hline EUREF-IG & 45 & & & \\
ITRF2000 & 24 & 36 & & \\
RGP & 18 & 8 & 23 & \\
REGAL & 24 & 17 & 17 & 32 \\
\hline
\end{tabular}

where $\Sigma_{\text {uncons }}^{-1}, \Sigma_{\text {cons }}^{-1}, \Sigma_{\text {a priori }}^{-1}$ are, respectively, the inverses of the variance-covariance matrices of, respectively, the resulting unconstrained solution, the constrained solution and the 'a priori' constraints that were applied to the original solution. At this step, the reference frame is only 'loosely' defined through the final IGS orbits, which were kept fixed during the GPS analysis. The unconstrained variance matrix $\Sigma_{\text {uncons }}^{-1}$ contains both contributions from the natural measurement noise and from the reference system effect. This latter contribution can be reduced by adding so-called 'minimal constraints'. Minimal constraints are the algebraic expression on the variance-covariance matrix that the reference frame implementation is performed through a geometric (usually seven parameters) transformation. Minimal constraints are added to the coordinate variance-covariance matrix using

$\Sigma_{m c}^{-1}=\Sigma_{\text {uncons }}^{-1}+B^{\mathrm{T}}\left(\Sigma_{\theta}\right)^{-1} B$

with $B$ being defined by

$B=\left(E^{\mathrm{T}} E\right)^{-1} E^{\mathrm{T}}$

$E=\left(\begin{array}{ccccccc}\cdot & \cdot & \cdot & . & . & \cdot & \cdot \\ 1 & 0 & 0 & x_{0}^{i} & 0 & z_{0}^{i} & -y_{0}^{i} \\ 0 & 1 & 0 & y_{0}^{i} & -z_{0}^{i} & 0 & x_{0}^{i} \\ 1 & 0 & 0 & z_{0}^{i} & y_{0}^{i} & -x_{0}^{i} & 0 \\ . & . & . & . & . & . & .\end{array}\right)$,

where $\left(x_{0}^{i}, y_{0}^{i}, z_{0}^{i}\right)_{i \in\{1, n\}}$ are the approximate coordinates of a subset of sites present in the weekly solution and defining a good network geometry (Altamimi et al. 2002; Sillard \& Boucher 2001). The associated unconstrained coordinate solution is given by 
Table 3. Sites included in combination.

\begin{tabular}{|c|c|c|c|c|c|c|}
\hline \multirow[t]{2}{*}{ Site } & \multirow[t]{2}{*}{ Country } & \multicolumn{4}{|c|}{ Solution } & \multirow{2}{*}{$\begin{array}{l}\text { Residuals } \\
\left(\mathrm{mm} \mathrm{yr}^{-1}\right)\end{array}$} \\
\hline & & EUREF-IG & REGAL & RGP & ITRF2000 & \\
\hline AJAC & France & 1.3 & 1.9 & 1.9 & & 0.6 \\
\hline BRST & France & 2.4 & 2.6 & 2.8 & & 1.2 \\
\hline FCLZ & France & & 3.2 & & & * \\
\hline CHTL & France & & 2.5 & & & * \\
\hline GINA & France & & 3.5 & 3.5 & & 0.4 \\
\hline GRAS & France & 4.7 & 5.7 & 3.6 & $\mathrm{x}$ & 0.9 \\
\hline MANS & France & 1.9 & 2.3 & 3.4 & & 0.6 \\
\hline MARS & France & 2.7 & 3.1 & 3.1 & & 0.5 \\
\hline $\mathrm{MICH}$ & France & & 3.1 & 3.0 & & 0.6 \\
\hline MODA & France & & 2.9 & 2.8 & & 0.4 \\
\hline MTPL & France & & 2.3 & 2.3 & & 0.5 \\
\hline SJDV & France & 2.9 & 3.9 & 3.6 & & 0.5 \\
\hline STJ9 & France & & 1.9 & 1.7 & & 0.3 \\
\hline TOUL & France & 3.5 & 4.0 & 3.0 & $\mathrm{x}$ & 0.6 \\
\hline ONSA & Sweden & 3.3 & & & $\mathrm{x}$ & 0.5 \\
\hline HFLK & Austria & 4.9 & 5.4 & & & 0.6 \\
\hline GRAZ & Austria & 3.3 & 5.7 & & $\mathrm{x}$ & 0.7 \\
\hline SOFI & Bulgaria & 4.0 & & & $\mathrm{x}$ & 0.8 \\
\hline PENC & Hungary & 4.9 & & & $\mathrm{x}$ & 0.8 \\
\hline GOPE & Czech Rep. & 4.9 & & & $\mathrm{x}$ & 0.1 \\
\hline BOGO & Poland & 5.0 & & & $\mathrm{x}$ & 0.1 \\
\hline BOR1 & Poland & 5.0 & & & $\mathrm{x}$ & 0.5 \\
\hline JOZE & Poland & 4.9 & 5.7 & & $\mathrm{x}$ & 0.4 \\
\hline LAMA & Poland & & & & $\mathrm{x}$ & * \\
\hline WROC & Poland & 2.6 & & & & * \\
\hline BZRG & Italy & 2.5 & & & & $*$ \\
\hline CAGL & Italy & 4.9 & 5.5 & & $\mathrm{x}$ & 0.3 \\
\hline GENO & Italy & 2.5 & 4.3 & & & 0.4 \\
\hline LAMP & Italy & 2.0 & & & & 1.3 \\
\hline MATE & Italy & 3.3 & & & $\mathrm{x}$ & 0.7 \\
\hline MEDI & Italy & & 5.5 & & $\mathrm{x}$ & 0.3 \\
\hline NOTO & Italy & 4.1 & 4.8 & & $\mathrm{x}$ & 0.6 \\
\hline TORI & Italy & 2.4 & 4.9 & & & 0.4 \\
\hline UNPG & Italy & 2.4 & & & & * \\
\hline UPAD & Italy & 4.8 & 5.7 & 3.6 & $\mathrm{x}$ & 0.5 \\
\hline VENE & Italy & 4.3 & & & & $*$ \\
\hline BRUS & Belgium & & & & $\mathrm{x}$ & $*$ \\
\hline DENT & Belgium & 3.0 & & 3.4 & & 0.1 \\
\hline WARE & Belgium & 3.4 & & 1.9 & & 0.2 \\
\hline ALAC & Spain & 1.8 & & 2.0 & & 0.7 \\
\hline BELL & Spain & 2.0 & & 2.0 & & 0.2 \\
\hline EBRE & Spain & 4.7 & 5.6 & 3.6 & $\mathrm{x}$ & 0.9 \\
\hline ESCO & Spain & 1.6 & & 2.0 & & 0.6 \\
\hline MADR & Spain & & & & $\mathrm{x}$ & $*$ \\
\hline SFER & Spain & 2.6 & 5.4 & 3.6 & $\mathrm{x}$ & 0.9 \\
\hline VILL & Spain & 4.9 & 5.7 & & $\mathrm{x}$ & 0.5 \\
\hline DELF & Netherlands & 3.0 & & & & $*$ \\
\hline KOSG & Netherlands & 2.2 & 5.7 & & $\mathrm{x}$ & 0.4 \\
\hline WSRT & Netherlands & 3.9 & 4.2 & & $\mathrm{x}$ & 0.4 \\
\hline CASC & Portugal & 1.7 & & 2.9 & $\mathrm{x}$ & 2.3 \\
\hline ZIMM & Switzerland & 1.9 & 5.7 & 2.7 & $\mathrm{x}$ & 0.7 \\
\hline 7203 & Germany & & & & $\mathrm{x}$ & $*$ \\
\hline KARL & Germany & 2.7 & & & & $*$ \\
\hline OBER & Germany & 4.4 & 4.8 & & $\mathrm{x}$ & 0.5 \\
\hline POTS & Germany & 4.8 & 5.7 & & $\mathrm{x}$ & 1.0 \\
\hline WTZR & Germany & 3.4 & 5.6 & 3.6 & $\mathrm{x}$ & 0.5 \\
\hline METS & Finland & & & & $\mathrm{x}$ & $*$ \\
\hline MOPI & Slovak Rep. & 4.6 & & & & $*$ \\
\hline RIGA & Latvia & & & & $\mathrm{x}$ & $*$ \\
\hline MDVO & Russia & & & & $\mathrm{x}$ & $*$ \\
\hline ZWEN & Russia & & & & $\mathrm{x}$ & $*$ \\
\hline 7561 & Ukraine & & & & $\mathrm{x}$ & $*$ \\
\hline GLSV & Ukraine & & & & $\mathrm{x}$ & $*$ \\
\hline HERS & United Kingdom & & & & $\mathrm{x}$ & $*$ \\
\hline
\end{tabular}

Columns 3-5 units are decimal years indicating the data time span used for the velocity determination in each individual solution. The last column is the largest residual on the horizontal velocity components obtained in the combination. * means that only one solution contributes to the velocity determination. 
Table 4. Scaling factor applied to individual solution variance in the combination.

\begin{tabular}{lr}
\hline Solution & Factor \\
\hline EUREF-IG & 5.7 \\
ITRF2000 & 1.7 \\
RGP & 5.3 \\
REGAL & 11.9 \\
\hline
\end{tabular}

$X_{\text {uncons }}=\Sigma_{m c}^{-1}\left[\Sigma_{\text {cons }}^{-1} X_{\text {cons }}-\Sigma_{\text {a priori }}^{-1} X_{\text {a priori }}\right]$,

where $X_{\text {uncons }}, X_{\text {cons }}$ and $X_{\text {apriori }}$ are, respectively, the vector of unconstrained, constrained and a priori coordinates. Using the unconstrained weekly solutions with their associated minimally constrained variance matrices, we then simultaneously compute a position-velocity solution using the following equation:

$X_{t_{s}}^{i}=X_{\mathrm{sol}}^{i}+\left(t_{s}-t_{0}\right) \dot{X}_{\mathrm{sol}}^{i}+T_{s}+D_{s} X_{\mathrm{sol}}^{i}+R_{s} X_{\mathrm{sol}}^{i}$,

where $X_{t_{s}}^{i}$ is the position of site $i$ of the weekly solution $s$ at epoch $t_{s}, X_{\text {sol }}^{i}$ is the estimated position at the chosen epoch of combination $t_{0}, \dot{X}_{\text {sol }}^{i}$ is the estimated velocity, and $T_{s}, D_{s}$ and $R_{s}$ are the estimated seven transformation parameters between the resulting and the weekly solutions at epoch $t_{s}$. Since velocities are estimated, the temporal evolution of the reference frame must also be defined for eq. (6) to be solvable. This is done by applying a condition that $\left(T_{s}\right.$, $D_{s}, R_{s}$ ) $=0$ at two epochs of the time-series (for instance, at its beginning and end). The position time-series $X_{i}(t)$ of site $i$ is derived using

$X_{i}(t)=X_{\mathrm{sol}}^{i}+\dot{X}_{\mathrm{sol}}^{i}\left(t-t_{0}\right)+v_{i}(t)$,

where $v_{i}(t)$ is the residual in eq. (6) for site $i$ at time $t$ of the weekly solution.

For both EUREF-EPN and RGP data, we notice that unexplained jumps in the time-series can impact the velocity estimate at a $1 \mathrm{~mm}$ $\mathrm{yr}^{-1}$ level. In order to minimize this problem, we solve for two different positions (before and after the jump) for a point but constrain the velocity to be identical for the entire time-series. By doing so, we take benefit of the whole time span available for the velocity estimation. We also exclude EUREF data before GPS week 860 (1996 July) because of a jump in the time-series at most sites, probably caused by the change from ITRF93 to ITRF94 in the estimation of precise orbits by the IGS. Hereafter, we name 'EUREF-IG' our solution derived from the EUREF-EPN network.

\subsubsection{REGAL solution}

The daily solutions used in this study (REGAL) are handled differently. We first pass the loosely constrained daily estimates and their associated variance-covariance matrices to a Kalman filter (GLOBK, Herring et al. 1990) in order to estimate velocities and positions. At this stage, we apply tight constraints on orbits and Earth orientation parameters (EOP), but loose constraints on site positions $(100 \mathrm{~m})$ and velocities $\left(10 \mathrm{~m} \mathrm{yr}^{-1}\right)$ at all stations. We obtain a loosely constrained position-velocity solution, to which we apply minimal constraints on positions and velocities as defined above. A previous REGAL solution including fewer sites and a shorter data time span produced using this same strategy, submitted and included in the ITRF2000 definition, showed a wrms of $0.6 \mathrm{~mm} \mathrm{yr}^{-1}$ on horizontal velocities.

\section{COMBINATION}

Combining the results from several networks and/or analysis centres provides a number of advantages over the analysis of each solution independently. First, it minimizes possible systematic errors associated with each processing strategy taken individually. Secondly, sites shared by several solutions provide a way to tie these solutions into a single and consistent velocity field (Table 2). These common sites also serve to cross-check individual solutions and detect outliers. Thirdly, reference frame constraints applied in individual geodetic solutions can modify the original relative velocity significantly in the individual solutions (Sillard \& Boucher 2001). The combination methodology presented above handles reference frame constraints simultaneously for all individual solutions in a rigorous way. Because we only use 14-parameter transformations and minimally constrained solutions in the combination, relative positions and velocities of individual solution are not affected by the reference frame definition. Finally, we apply a weighting scheme that rescales the variance-covariance matrices of each individual solution and provides realistic formal errors (Table 4).

\subsection{Methodology}

The input data to the combination consists of individual solutions with minimal constraints applied (see above). We use a combination methodology similar to that used for the definition of the ITRF (Altamimi et al. 2002). For each site $i$ in solution $s$ ( $s=$ RGP, REGAL, EUREF-IG, ITRF2000), we simultaneously estimate the position $X_{\text {comb }}^{i}$ at epoch $t_{0}$ (epoch of the combination), the velocity $\dot{X}_{\text {comb }}^{i}$, and a 14-parameter transformation between the individual and the combined solution using (after Altamimi et al. 2002):

$$
\begin{aligned}
X_{s}^{i}= & X_{\mathrm{comb}}^{i}+\left(t_{s}-t_{0}\right) \dot{X}_{\mathrm{comb}}^{i} \\
& +T_{k}+D_{k} X_{\mathrm{comb}}^{i}+R_{k} X_{\mathrm{comb}}^{i} \\
& +\left(t_{s}-t_{k}\right)\left[\dot{T}_{k}+\dot{D}_{k} X_{\mathrm{comb}}^{i}+\dot{R}_{k} X_{\mathrm{comb}}^{i}\right] \\
\dot{X}_{s}^{i}= & \dot{X}_{\mathrm{comb}}^{i}+\dot{T}_{k}+\dot{D}_{k} X_{\mathrm{comb}}^{i}+\dot{R}_{k} X_{\mathrm{comb}}^{i},
\end{aligned}
$$

where $X^{i}{ }_{s}$ is the position of site $i$ in solution $s$ at epoch $t_{s}, X_{\text {comb }}^{i}$ is the estimated position of site $i$ at epoch $t_{0}$ and $\dot{X}_{\text {comb }}^{i}$ is its final velocity in the combination. $T_{k}, D_{k}, R_{k}$ and $\dot{T}_{k}, \dot{D}_{k}, \dot{R}_{k}$ are the transformation parameters between individual solutions $s$ and the combined solution and their time derivatives. $t_{s}$ is the epoch of minimal position variance for the solution $s$, which is generally the middle point of the observation time span included in the solution. $t_{k}$ is the epoch of expression of the transformation parameters. The reference frame definition in the combination is implemented by imposing the 14-parameter transformation between ITRF2000 and the combined solution to be zero (no translation, scalefactor or rotation and no rate of change of these parameters). Our velocity field is therefore expressed in the ITRF2000 reference frame. From this preliminary combination, an a posteriori variance factor $\sigma_{s}^{2}$ for each individual solution $s$ is estimated in the inversion, which is then applied to the variance-covariance matrix of the corresponding individual solution in an iterative way until both individual $\sigma_{s}^{2}$ and the global a posteriori variance factor equals 1 (Helmert variance component estimation, Table 4, see Altamimi et al. 2002 for details). Normal residuals in the combination are used for outliers detection.

\subsection{Quality assessment of the results}

The velocities resulting from the final combination are given in Table 5. The wrms of each individual solution for horizontal and 
Table 5. Velocity values from the combination of the EUREF-IG, REGAL and RGP permanent GPS solutions with a selection of ITRF2000 sites.

\begin{tabular}{|c|c|c|c|c|c|c|c|c|c|}
\hline \multirow[b]{3}{*}{ Site } & & & \multicolumn{4}{|c|}{ Velocity } & & & \\
\hline & \multicolumn{2}{|c|}{ Position } & \multicolumn{2}{|c|}{ ITRF2000 } & \multicolumn{2}{|c|}{ Central Eur. } & \multicolumn{3}{|c|}{ Standard deviation } \\
\hline & long. & lat. & $V_{e}$ & $V_{n}$ & $V_{e}$ & $V_{n}$ & $\sigma_{V_{e}}$ & $\sigma_{V_{n}}$ & $\sigma_{V_{e n}}$ \\
\hline 7203 & 6.88 & 50.52 & 19.48 & 14.60 & 0.71 & -0.31 & 0.40 & 0.38 & -0.04 \\
\hline 7561 & 33.99 & 44.42 & 24.83 & 10.88 & 0.20 & -0.16 & 0.62 & 0.69 & -0.03 \\
\hline AJAC & 8.76 & 41.93 & 21.01 & 14.80 & -0.11 & 0.05 & 0.61 & 0.75 & -0.02 \\
\hline ALAC & -0.48 & 38.34 & 20.19 & 14.95 & -0.11 & -0.49 & 0.46 & 0.54 & 0.04 \\
\hline BELL & 1.40 & 41.60 & 19.81 & 14.14 & -0.10 & -1.19 & 0.45 & 0.54 & -0.02 \\
\hline BOGO & 21.04 & 52.48 & 21.13 & 13.42 & 0.12 & 0.16 & 0.19 & 0.23 & 0.00 \\
\hline BOR1 & 17.07 & 52.28 & 19.84 & 13.65 & -0.48 & -0.16 & 0.15 & 0.17 & -0.01 \\
\hline BRST & -4.50 & 48.38 & 17.49 & 15.54 & 0.44 & -0.06 & 0.38 & 0.42 & -0.04 \\
\hline BRUS & 4.36 & 50.80 & 18.01 & 14.29 & -0.17 & -0.83 & 0.23 & 0.24 & -0.02 \\
\hline BZRG & 11.34 & 46.50 & 19.91 & 13.96 & -0.69 & -0.53 & 0.57 & 0.68 & 0.00 \\
\hline CASC & -9.42 & 38.69 & 17.84 & 13.81 & -0.87 & -1.90 & 0.42 & 0.45 & 0.03 \\
\hline CAGL & 8.97 & 39.14 & 21.41 & 14.62 & -0.28 & -0.12 & 0.19 & 0.19 & -0.01 \\
\hline CHTL & 6.36 & 45.30 & 20.42 & 14.11 & 0.47 & -0.86 & 0.86 & 0.92 & 0.04 \\
\hline DELF & 4.39 & 51.99 & 17.76 & 14.94 & -0.11 & -0.17 & 0.30 & 0.40 & -0.04 \\
\hline DENT & 3.40 & 50.93 & 16.72 & 16.07 & -1.23 & 0.88 & 0.25 & 0.31 & -0.03 \\
\hline EBRE & 0.49 & 40.82 & 19.85 & 14.84 & -0.07 & -0.54 & 0.17 & 0.18 & 0.03 \\
\hline ESCO & 0.98 & 42.69 & 19.76 & 14.80 & 0.17 & -0.55 & 0.52 & 0.66 & 0.00 \\
\hline FCLZ & 5.99 & 45.64 & 20.12 & 14.58 & 0.31 & -0.42 & 0.63 & 0.69 & 0.01 \\
\hline GENO & 8.92 & 44.42 & 20.69 & 15.00 & 0.07 & 0.26 & 0.43 & 0.47 & 0.01 \\
\hline GINA & 5.79 & 43.68 & 19.96 & 15.34 & -0.27 & 0.33 & 0.21 & 0.25 & -0.04 \\
\hline GLSV & 30.50 & 50.36 & 22.35 & 10.91 & -0.73 & -0.78 & 1.06 & 1.15 & 0.04 \\
\hline GOPE & 14.79 & 49.91 & 20.58 & 14.20 & 0.12 & 0.10 & 0.21 & 0.25 & 0.02 \\
\hline GRAS & 6.92 & 43.75 & 20.37 & 14.42 & -0.05 & -0.50 & 0.12 & 0.13 & -0.03 \\
\hline GRAZ & 15.49 & 47.07 & 22.20 & 14.25 & 0.97 & 0.24 & 0.13 & 0.15 & -0.04 \\
\hline HERS & 0.34 & 50.87 & 18.14 & 15.76 & 0.80 & 0.37 & 0.17 & 0.19 & -0.01 \\
\hline HFLK & 11.39 & 47.31 & 21.15 & 14.95 & 0.72 & 0.45 & 0.15 & 0.18 & -0.04 \\
\hline JOZE & 21.03 & 52.10 & 21.37 & 13.17 & 0.27 & -0.09 & 0.16 & 0.18 & -0.01 \\
\hline KARL & 8.41 & 49.01 & 19.73 & 14.91 & 0.27 & 0.12 & 0.41 & 0.55 & -0.01 \\
\hline KOSG & 5.81 & 52.18 & 17.80 & 15.23 & -0.31 & 0.22 & 0.16 & 0.16 & -0.04 \\
\hline LAMA & 20.67 & 53.89 & 19.85 & 13.59 & -0.76 & 0.28 & 0.23 & 0.27 & 0.02 \\
\hline LAMP & 12.61 & 35.50 & 21.12 & 16.97 & -1.74 & 2.61 & 0.68 & 0.73 & -0.03 \\
\hline MANS & 0.16 & 48.02 & 17.08 & 15.57 & -1.01 & 0.18 & 0.28 & 0.33 & -0.03 \\
\hline MADR & -4.25 & 40.43 & 18.92 & 15.63 & -0.27 & 0.04 & 0.28 & 0.30 & -0.09 \\
\hline MARS & 5.35 & 43.28 & 19.88 & 14.56 & -0.36 & -0.49 & 0.22 & 0.27 & -0.01 \\
\hline MATE & 16.70 & 40.65 & 23.78 & 18.07 & 1.12 & 4.21 & 0.14 & 0.14 & -0.06 \\
\hline MDVO & 37.22 & 56.03 & 23.62 & 11.35 & 0.70 & 0.97 & 0.42 & 0.51 & 0.06 \\
\hline MEDI & 11.65 & 44.52 & 23.53 & 16.24 & 2.44 & 1.78 & 0.17 & 0.17 & -0.03 \\
\hline METS & 24.40 & 60.22 & 20.23 & 11.67 & 0.57 & -1.07 & 0.25 & 0.24 & 0.00 \\
\hline MICH & 5.72 & 43.92 & 20.96 & 14.41 & 0.80 & -0.61 & 0.26 & 0.32 & -0.04 \\
\hline MODA & 6.71 & 45.21 & 21.06 & 13.62 & 1.01 & -1.32 & 0.28 & 0.36 & -0.06 \\
\hline MTPL & 3.86 & 43.64 & 20.51 & 14.82 & 0.63 & -0.34 & 0.41 & 0.50 & -0.02 \\
\hline MOPI & 17.27 & 48.37 & 20.92 & 14.26 & -0.34 & 0.47 & 0.34 & 0.45 & 0.00 \\
\hline NOTO & 14.99 & 36.88 & 20.82 & 17.70 & -2.19 & 3.62 & 0.17 & 0.17 & -0.03 \\
\hline OBER & 11.28 & 48.09 & 20.24 & 14.54 & 0.01 & 0.04 & 0.17 & 0.19 & -0.03 \\
\hline ONSA & 11.93 & 57.40 & 17.30 & 13.62 & -0.63 & -0.80 & 0.12 & 0.12 & -0.04 \\
\hline PENC & 19.28 & 47.79 & 22.35 & 13.46 & 0.61 & -0.05 & 0.18 & 0.21 & -0.01 \\
\hline POTS & 13.07 & 52.38 & 19.68 & 14.26 & 0.16 & -0.04 & 0.13 & 0.14 & -0.03 \\
\hline RIGA & 24.06 & 56.95 & 21.08 & 13.06 & 0.61 & 0.27 & 0.95 & 1.21 & 0.03 \\
\hline SFER & -6.21 & 36.46 & 17.52 & 16.61 & -2.25 & 0.96 & 0.32 & 0.31 & 0.06 \\
\hline SJDV & 4.68 & 45.88 & 19.58 & 14.90 & 0.07 & -0.20 & 0.18 & 0.22 & -0.03 \\
\hline SOFI & 23.39 & 42.56 & 24.50 & 10.82 & 1.11 & -2.09 & 0.33 & 0.36 & -0.03 \\
\hline STJ9 & 7.68 & 48.62 & 19.81 & 14.82 & 0.40 & -0.03 & 0.53 & 0.67 & -0.03 \\
\hline TORI & 7.66 & 45.06 & 20.28 & 13.84 & 0.03 & -1.02 & 0.39 & 0.42 & 0.00 \\
\hline TOUL & 1.48 & 43.56 & 19.47 & 15.29 & 0.00 & -0.03 & 0.20 & 0.22 & 0.00 \\
\hline UNPG & 12.36 & 43.12 & 21.20 & 15.71 & -0.29 & 1.33 & 0.60 & 0.72 & -0.02 \\
\hline UPAD & 11.88 & 45.41 & 21.65 & 16.43 & 0.71 & 2.00 & 0.13 & 0.15 & -0.04 \\
\hline VENE & 12.33 & 45.44 & 21.32 & 16.56 & 0.31 & 2.17 & 0.24 & 0.30 & -0.01 \\
\hline VILL & -3.95 & 40.44 & 18.92 & 15.26 & -0.31 & -0.33 & 0.18 & 0.17 & 0.03 \\
\hline WARE & 5.25 & 50.69 & 18.53 & 14.98 & 0.13 & -0.07 & 0.26 & 0.34 & -0.02 \\
\hline WROC & 17.06 & 51.11 & 20.19 & 14.13 & -0.41 & 0.32 & 0.40 & 0.53 & 0.05 \\
\hline
\end{tabular}


Table 5. Continued.

\begin{tabular}{|c|c|c|c|c|c|c|c|c|c|}
\hline \multirow[b]{3}{*}{ Site } & & & \multicolumn{4}{|c|}{ Velocity } & & & \\
\hline & \multicolumn{2}{|c|}{ Position } & \multicolumn{2}{|c|}{ ITRF2000 } & \multicolumn{2}{|c|}{ Central Eur. } & \multicolumn{3}{|c|}{ Standard deviation } \\
\hline & long. & lat. & $V_{e}$ & $V_{n}$ & $V_{e}$ & $V_{n}$ & $\sigma_{V_{e}}$ & $\sigma_{V_{n}}$ & $\sigma_{V_{e n}}$ \\
\hline WSRT & 6.60 & 52.91 & 17.86 & 15.13 & -0.20 & 0.19 & 0.19 & 0.23 & -0.02 \\
\hline WTZR & 12.88 & 49.14 & 20.25 & 14.29 & -0.03 & -0.03 & 0.11 & 0.11 & -0.07 \\
\hline ZIMM & 7.47 & 46.88 & 20.75 & 15.03 & 0.95 & 0.15 & 0.13 & 0.15 & -0.05 \\
\hline ZWEN & 36.76 & 55.70 & 23.05 & 10.68 & 0.13 & 0.20 & 0.43 & 0.35 & -0.03 \\
\hline
\end{tabular}

Velocities are expressed in ITRF2000. Residuals velocity in a Central Europe reference frame are computed by removing a rigid rotation estimated from BOGO, BOR1, GOPE, JOZE, POTS, WROC, OBER, WSRT, WTZR, RIGA, ZWEN, 7561 (Simeis). long., lat.: longitude and latitude in decimal degrees. $V_{e}, V_{n}$ : horizontal velocity component (east, north, respectively) in $\mathrm{mm} \mathrm{yr}^{-1} . \sigma_{V_{e}}$, $\sigma_{V_{n}}$ : standard deviation of horizontal velocity components in $\mathrm{mm} \mathrm{yr}^{-1} \cdot \sigma_{V_{e n}}$ : correlation coefficient between $V_{e}$ and $V_{n}$.

Table 6. WRMS of individual solutions in the combination.

\begin{tabular}{lccccc}
\hline Solution & \multicolumn{2}{c}{ Position $(\mathrm{mm})$} & & \multicolumn{2}{c}{ Velocity $\left(\mathrm{mm} \mathrm{yr}^{-1}\right)$} \\
\cline { 2 - 3 } & Horizontal & Up & & Horizontal & Up \\
\hline EUREF-IG & 0.3 & 2.6 & & 0.2 & 2.7 \\
ITRF2000 & 0.4 & 3.1 & & 0.2 & 1.1 \\
RGP & 0.2 & 2.0 & & 0.2 & 3.1 \\
REGAL & 1.1 & 1.3 & & 0.4 & 0.6 \\
\hline
\end{tabular}

vertical position and velocity components provides a first assessment of the solution accuracy (Table 6). We find that all the solutions used here have a wrms on horizontal velocities of less than $0.4 \mathrm{~mm} \mathrm{yr}^{-1}$.

The solution accuracy can also be assessed using the level of agreement between solutions, given by the wrms in the combination for each site (Table 3). For most sites, we find an agreement between solutions of the order of $0.5 \mathrm{~mm} \mathrm{yr}^{-1}$. CASC (Cascais), however, shows a disagreement between EUREF-IG, RGP and ITRF2000 of about $2.5 \mathrm{~mm} \mathrm{yr}^{-1}$. We will consequently not include that site in the tectonic interpretation below. Also, we find that the EUREF-IG and REGAL solutions disagree on the east component at LAMP (Lampedusa, difference $1.5 \mathrm{~mm} \mathrm{yr}^{-1}$ ). However, the velocity residual at this site in a stable Europe reference frame (see below) remains significant enough $\left(3.1 \mathrm{~mm} \mathrm{yr}^{-1}\right)$ (Table 3$)$ to be used in our tectonic interpretation.

Formal errors in geodetic solutions are usually based on a single network processing and are, at best, an internal indicator of precision. In our case, the formal errors of the combined solution depend on the variance of the individual solutions before combination but also on the level of agreement between solutions in the combination. Therefore, we believe that the formal errors of the combination are a reliable indicator of its accuracy. We find formal errors on horizontal velocities lower than $1 \mathrm{~mm} \mathrm{yr}^{-1}$ at all sites except RIGA and GLSV (Table 3). The best determined sites have a formal error (standard deviation) of about $0.2 \mathrm{~mm} \mathrm{yr}^{-1}$ on horizontal velocities.

\section{INTERPRETATION}

\subsection{Plate interior rigidity assessment}

\subsubsection{Velocity field statistical analysis}

Nocquet et al. (2001) have shown that the use of the NNRNUVEL1A plate model to define a Eurasia-fixed reference frame for mapping residual geodetic velocity could cause a bias reaching $3 \mathrm{~mm}$ $\mathrm{yr}^{-1}$ in Western Europe. Altamimi \& Boucher (2001) found a dif-
Table 7. Results of an automatic search of stable sites.

\begin{tabular}{|c|c|c|c|c|c|c|}
\hline \multirow[t]{2}{*}{ Site } & \multirow[t]{2}{*}{$V_{e}$} & \multirow[t]{2}{*}{$V_{n}$} & \multirow[t]{2}{*}{$\sigma_{V_{e}}$} & \multirow[t]{2}{*}{$\sigma_{V_{n}}$} & \multicolumn{2}{|c|}{ Residuals } \\
\hline & & & & & $V_{e}$ & $V_{n}$ \\
\hline 7203 & 19.5 & 14.6 & 0.4 & 0.4 & 0.7 & -0.3 \\
\hline 7561 & 24.8 & 10.9 & 0.6 & 0.7 & 0.2 & -0.2 \\
\hline AJAC & 21.0 & 14.8 & 0.6 & 0.7 & -0.1 & 0.0 \\
\hline ALAC & 20.2 & 15.0 & 0.5 & 0.5 & 0.0 & -0.5 \\
\hline BOGO & 21.1 & 13.4 & 0.2 & 0.2 & 0.1 & 0.1 \\
\hline BRST & 17.5 & 15.5 & 0.4 & 0.4 & 0.5 & -0.1 \\
\hline CAGL & 21.4 & 14.6 & 0.2 & 0.2 & -0.2 & -0.1 \\
\hline ESCO & 19.8 & 14.8 & 0.5 & 0.7 & 0.2 & -0.6 \\
\hline FCLZ & 20.1 & 14.6 & 0.6 & 0.7 & 0.4 & -0.4 \\
\hline GENO & 20.7 & 15.0 & 0.4 & 0.5 & 0.1 & 0.2 \\
\hline GINA & 20.0 & 15.3 & 0.2 & 0.3 & -0.2 & 0.3 \\
\hline GOPE & 20.6 & 14.2 & 0.2 & 0.3 & 0.2 & 0.1 \\
\hline JOZE & 21.4 & 13.2 & 0.2 & 0.2 & 0.3 & -0.1 \\
\hline KARL & 19.7 & 14.9 & 0.4 & 0.6 & 0.3 & 0.1 \\
\hline KOSG & 17.8 & 15.2 & 0.2 & 0.2 & -0.3 & 0.2 \\
\hline MADR & 18.9 & 15.6 & 0.3 & 0.3 & -0.2 & 0.0 \\
\hline MTPL & 20.5 & 14.8 & 0.4 & 0.5 & 0.7 & -0.4 \\
\hline OBER & 20.2 & 14.5 & 0.2 & 0.2 & 0.1 & 0.0 \\
\hline TOUL & 19.5 & 15.3 & 0.2 & 0.2 & 0.1 & -0.1 \\
\hline POTS & 19.7 & 14.3 & 0.1 & 0.1 & 0.2 & -0.1 \\
\hline MOPI & 20.9 & 14.3 & 0.3 & 0.4 & -0.3 & 0.5 \\
\hline RIGA & 21.1 & 13.1 & 0.9 & 1.2 & 0.6 & 0.3 \\
\hline STJ9 & 19.8 & 14.8 & 0.5 & 0.7 & 0.4 & -0.1 \\
\hline VILL & 18.9 & 15.3 & 0.2 & 0.2 & -0.3 & -0.4 \\
\hline WROC & 20.2 & 14.1 & 0.4 & 0.5 & -0.4 & 0.3 \\
\hline WSRT & 17.9 & 15.1 & 0.2 & 0.2 & -0.2 & 0.2 \\
\hline WARE & 18.5 & 15.0 & 0.3 & 0.3 & 0.2 & -0.1 \\
\hline WTZR & 20.2 & 14.3 & 0.1 & 0.1 & 0.0 & 0.0 \\
\hline ZWEN & 23.1 & 10.7 & 0.4 & 0.3 & 0.1 & 0.2 \\
\hline
\end{tabular}

wrms of residual velocities $\left(\mathrm{mm} \mathrm{yr}^{-1}\right): 0.4 \mathrm{~mm} \mathrm{yr}^{-1}$.

a posteriori variance factor: 0.96 .

ferential rotation rate between NNR-NUVEL1A and the ITRF2000 velocity fields in Europe leading to similar results. Consequently, the plate-fixed reference frame use for mapping geodetic velocities must be estimated from the geodetic data set itself. Even so, different estimation strategies and choice of sites used to define the stable plate interior can produce different results at a $1-2 \mathrm{~mm} \mathrm{yr}^{-1}$ level. In order to find an optimal solution to this problem and test the rigidity level of the Eurasian Plate interior level, we start our analysis of the velocity field by searching for the subset of sites that define the most rigid domain, first using a 'blind' statistical approach (Nocquet et al. 2001).

We search for the subset of sites with velocities that best fit a rigid rotation. We perform this search over all the possible site 
combinations. $\chi^{2}$ and minimal variance criteria indicate that the subset [POTS, BOGO, JOZE, GOPE, OBER, WTZR] provides the best fit to a rigid rotation, with residual velocities of less than $0.3 \mathrm{~mm} \mathrm{yr}^{-1}$. All of these sites belong to the supposedly tectonically stable part of the Eurasian plate and an area where a post-glacial rebound effect on the horizontal velocity probably does not exceed $0.2 \mathrm{~mm} \mathrm{yr}^{-1}$ (Peltier 1995). We then progressively augment this initial site subset by adding one site at a time and testing the consistency of the new subset with a rigid rotation using $\chi^{2}$ and $F$ ratio tests. We find that the 29-site subset shown in Table 7 satisfies these statistical tests, given their velocity uncertainties. The domain encompassing these sites extends from Central Europe to the westernmost part of Europe, including Spain and Sardinia. Velocity residuals at these 29 sites are less than $0.8 \mathrm{~mm} \mathrm{yr}^{-1}$. The overall wrms of the residual ve-
Table 8. Euler vector values for Europe: results of the automatic search algorithm.

\begin{tabular}{lcccccccc}
\hline \multicolumn{3}{c}{ Euler pole values } & & & \multicolumn{4}{c}{ Euler pole error ellipse } \\
\cline { 1 - 1 } \cline { 5 - 7 } latitude & longitude & $\omega$ & & a & $b$ & az & $\sigma_{\omega}$ \\
\hline 56.0 & -101.5 & 0.25 & & 0.69 & 0.15 & -153 & 0.001 \\
\hline
\end{tabular}

$\mathrm{a}=$ major semi axis, $\mathrm{b}=$ minor semi axis, $\mathrm{az}=$ azimuth of the major semi axis; latitude, longitude, $\mathrm{a}, \mathrm{b}$, az are in decimal degrees; $\omega$ and $\sigma_{\omega}$ are in $\operatorname{deg} \mathrm{Myr}^{-1}$.

locities is $0.4 \mathrm{~mm} \mathrm{yr}^{-1}$. The best-fitting Euler vector defined by this site subset is given in Table 8. Fig. 2 shows the residual velocities after subtracting the rigid rotation defined above from the velocities. It shows that velocities in the reference frame defined by the 29 -site

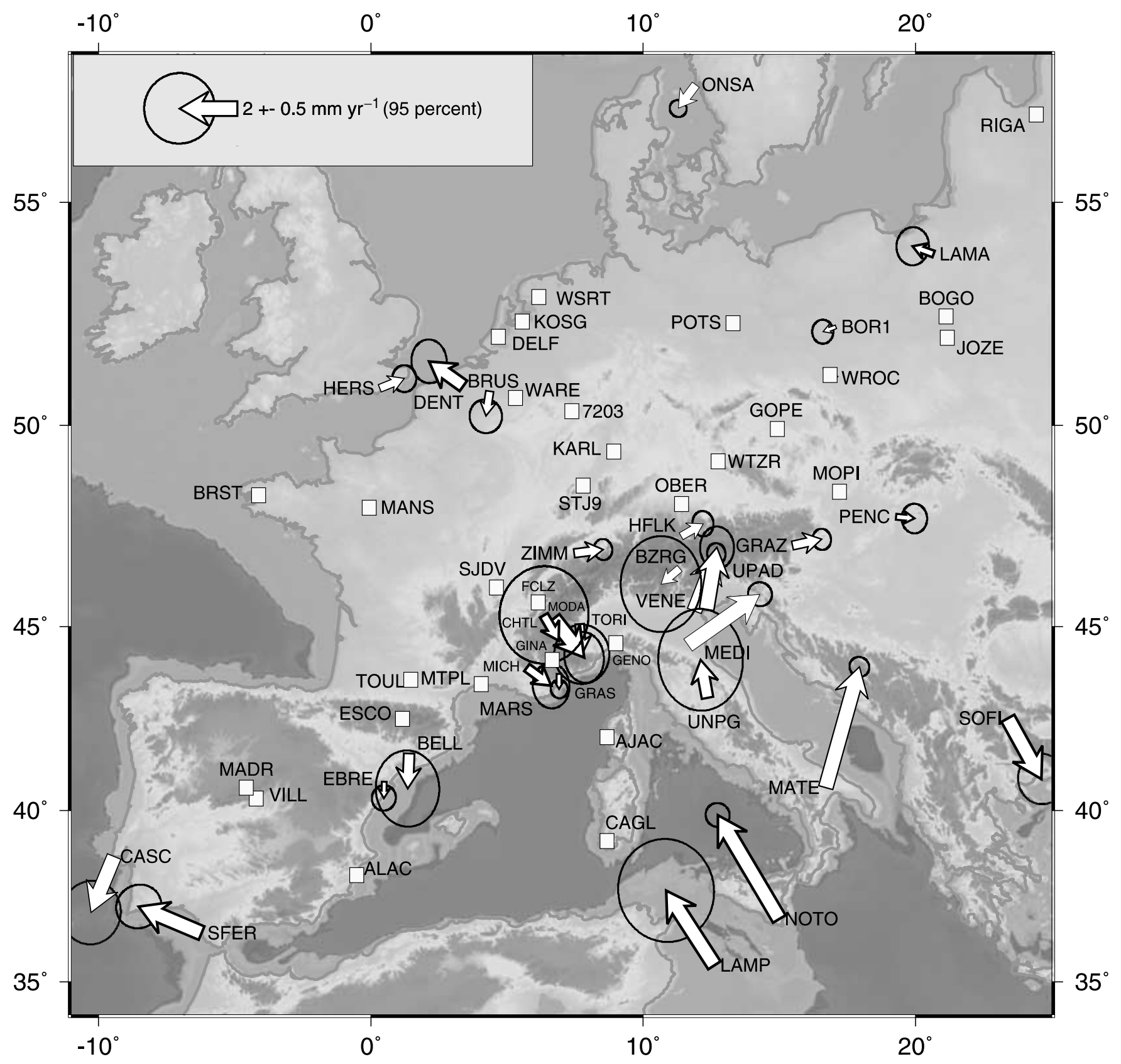

Figure 2. Automatic search for a rigid site subset. The white squares indicate geodetic sites that defines a rigid rotation, according to a 'blind' statistical algorithm. Residuals at these sites are less than $0.8 \mathrm{~mm} \mathrm{yr}^{-1}$. Residual velocities are shown for the others sites. To avoid clutter, ZWEN, MDVO, 7561, METS, GLSV are not included in this figure. 
Table 9. Euler vector estimation for Central Europe.

\begin{tabular}{lccccccc}
\hline \multicolumn{3}{c}{ Euler pole values } & & \multicolumn{4}{c}{ Euler pole error ellipse } \\
\cline { 1 - 3 } \cline { 6 - 8 } latitude & longitude & $\omega$ & & $\mathrm{a}$ & $\mathrm{b}$ & $\mathrm{az}$ & $\sigma_{\omega}$ \\
\hline 55.8 & -102.1 & 0.25 & & 0.91 & 0.14 & 149.7 & 0.003 \\
\hline
\end{tabular}

$\mathrm{a}=$ major semi axis, $\mathrm{b}=$ minor semi axis, az $=$ azimuth of the major semi axis; latitude, longitude, a, b, az are in decimal degrees; $\omega$ and $\sigma_{\omega}$ are in $\operatorname{deg} \mathrm{Myr}^{-1}$.

Table 10. Velocity residuals at the sites used to define the Central Europe rigid rotation.

\begin{tabular}{lcccc}
\hline Code & $\sigma_{V e}$ & $\sigma_{V n}$ & \multicolumn{2}{c}{ Residuals } \\
\cline { 4 - 5 } & & & $V_{e}$ & $V_{n}$ \\
\hline BOGO & 0.2 & 0.2 & 0.1 & 0.2 \\
BOR1 & 0.1 & 0.2 & -0.5 & -0.2 \\
GOPE & 0.2 & 0.3 & 0.1 & 0.1 \\
JOZE & 0.2 & 0.2 & 0.3 & -0.1 \\
POTS & 0.1 & 0.1 & 0.1 & 0.0 \\
WROC & 0.4 & 0.5 & -0.5 & 0.3 \\
OBER & 0.2 & 0.2 & 0.0 & 0.0 \\
WSRT & 0.2 & 0.2 & -0.2 & 0.2 \\
WTZR & 0.1 & 0.1 & 0.0 & 0.0 \\
RIGA & 0.9 & 1.2 & 0.6 & 0.3 \\
ZWEN & 0.4 & 0.3 & 0.1 & 0.2 \\
7561 & 0.6 & 0.7 & 0.2 & -0.2 \\
\hline
\end{tabular}

wrms: $0.4 \mathrm{~mm} \mathrm{yr}^{-1}$.

A posteriori variance factor: 1.25 .

subset significantly differs from zero at the sites located south of the Iberian Peninsula, in Italy, and in the Alps.

As a further check for possible intraplate deformation, we compute a rigid rotation for the sites located in Central Europe only, defined here as the area located north of the Alpine and Carpathian mountains ranges and east of the Rhine graben. This domain is commonly assumed to represent a tectonically stable part of the Eurasian plate over recent geological times ( $<1 \mathrm{Ma}$ ). We exclude the sites located in Fennoscandia because their velocities are influenced by post-glacial rebound at the level of $2-3 \mathrm{~mm} \mathrm{yr}^{-1}$ (Johansson et al. 2002). This 'manual' site selection now includes site BOR1 because of its small residual $\left(0.5 \pm 3 \mathrm{~mm} \mathrm{yr}^{-1}\right)$. We chose to discard site LAMA because of its large residual velocity $\left(0.9 \mathrm{~mm} \mathrm{yr}^{-1}\right)$ in the 29-site reference frame defined above, three times greater than its velocity formal error in our solution $\left(0.3 \mathrm{~mm} \mathrm{yr}^{-1}\right)$. Also, neighbouring sites such as BOG1, JOZE, BOGO or RIGA show a much smaller residual. Finally, there is no active geological structure that could explain such a local deviation from the overall rigid behaviour of the area. On the other hand, LAMA benefits from a rather long GPS observation history, with about 6 yr of continuous measurements, and is processed by six different analysis centres. We tentatively propose that the residual velocity at LAMA may be due to a local instability, possibly in the geodetic monumentation itself.

Using this new selection of sites, we estimate rotation parameters for Central Europe (Tables 9 and 10). Fig. 3 shows the residual velocities in this new Central Europe reference frame. We find a $0.4 \mathrm{~mm} \mathrm{yr}^{-1}$ overall wrms of the residual velocities, with a 0.7 $\mathrm{mm} \mathrm{yr}^{-1}$ maximum at site RIGA. We then test the significance of the residual velocities at the sites not included in the reference frame definition using the statistical tests described in Nocquet et al. (2001) (Table 11 and 12). We find that site ZWEN, near Moscow, perfectly fits the rigid rotation defined by our Central Europe site selection. Sites MDVO (vicinity of Moscow, Russia), GLSV (Kiev, Ukraine) and 7561 (Simeis, Crimea) also fit that rigid rotation within their uncertainties. We did not include site KARL (Karlsruhe) in our Central Europe selection because of its proximity to the Rhine graben, a tectonically active structure (e.g. Lemeille et al. 1999). However, we find that its velocity agrees at the $0.7 \mathrm{~mm} \mathrm{yr}^{-1}$ level with the rigid rotation defined by the Central Europe sites. Sites METS and ONSA show a significant velocity residual $(1.3 \pm 0.3$ $\mathrm{mm} \mathrm{yr}^{-1}$ in a SSE direction at METS and $1.2 \pm 0.3 \mathrm{~mm} \mathrm{yr}^{-1}$ in a SW direction at ONSA, Table 11), consistent with post-glacial rebound effects (Peltier 1995; Johansson et al. 2002). Sites GRAZ and PENC, located south of the Carpathians and Eastern Alps show a statistically significant residual velocity of $1.0 \pm 0.2 \mathrm{~mm} \mathrm{yr}^{-1}$ in a $80^{\circ} \mathrm{N}$ direction and $0.6 \pm 0.3 \mathrm{~mm} \mathrm{yr}^{-1}$ in a $90^{\circ} \mathrm{N}$ direction, respectively, with respect to Central Europe.

In summary, the results of these tests indicate that most of Western Europe behaves rigidly at the $0.4 \mathrm{~mm} \mathrm{yr}^{-1}$ level (wrms). This number is smaller than those previously obtained by Argus \& Gordon (1996) and Nocquet et al. (2001) and provide a new quantitative assessment of plate interior stability in Western Europe. In particular, it shows that post-glacial rebound influence on horizontal velocities is less than $0.4 \mathrm{~mm} \mathrm{yr}^{-1}$ for the part of Europe located south of Fennoscandia, which is an additional quantitative constraint for post-glacial rebound models (e.g. Milne et al. 2001).

\subsubsection{Intraplate deformation in Western Europe}

Nocquet et al. (2001) found a residual velocity of $1-2 \mathrm{~mm} \mathrm{yr}^{-1}$ with respect to Central Europe at three sites located west of the lower Rhine graben in Belgium and the Netherlands (KOSG, HERS, BRUS). In this previous study, only four sites in this area (KOSG, HERS, BRUS, 7203) fulfilled the quality criteria imposed in the ITRF site selection. In the present study, eight of the ITRF sites are now fulfilling our quality criteria, thanks to longer data time spans in the ITRF2000 solution. The statistical tests (Table 11) show that only three of these eight sites (DENT, HERS, BRUS) have a significant residual velocity with respect to Central Europe. However, the direction of the residual velocities is not consistent between the three sites, making a tectonic interpretation difficult. KOSG is the best determined site in this area, with six SLR and nine GPS solutions in ITRF2000, in addition to the EUREF-IG and REGAL solutions. Our statistical tests indicate that its velocity is consistent with Central Europe at the 95 per cent confidence level.

France, outside well-known active deformation areas such as the western Alps, the Jura, the Pyrenees, and the Rhine graben, is characterized by a low level of diffuse seismicity, mainly located in Brittany, Normandy and in the Massif Central (Nicolas et al. 1990, Fig. 1). We find no significant individual residual motion at the sites located in France (BRST, SJDV, TOUL, MTPL) in a Central Europe reference frame. The only exception is the MANS site, located on the roof of a $15 \mathrm{~m}$ tall building on unconsolidated sediments, the stability of which may be questioned. All other sites have residual velocities of less than $0.6 \mathrm{~mm} \mathrm{yr}^{-1}$ (maximum $0.7 \pm 0.6 \mathrm{~mm} \mathrm{yr}^{-1}$ at MTPL), that remain inside their uncertainty. The estimation of two Euler poles rather than one (one for the sites located in Central Europe and one for sites located west of the Rhine graben and the Alps) improves the fit to the velocity but decreasing $\chi^{2}$ is not found statistically significant by an F test, as found by Sella et al. (2002). Although it still indicates some E-W extension in the Rhine graben, it is not found to be significant. We conclude that the stable part of France (outside the Alps and Jura) is rigidly attached to 


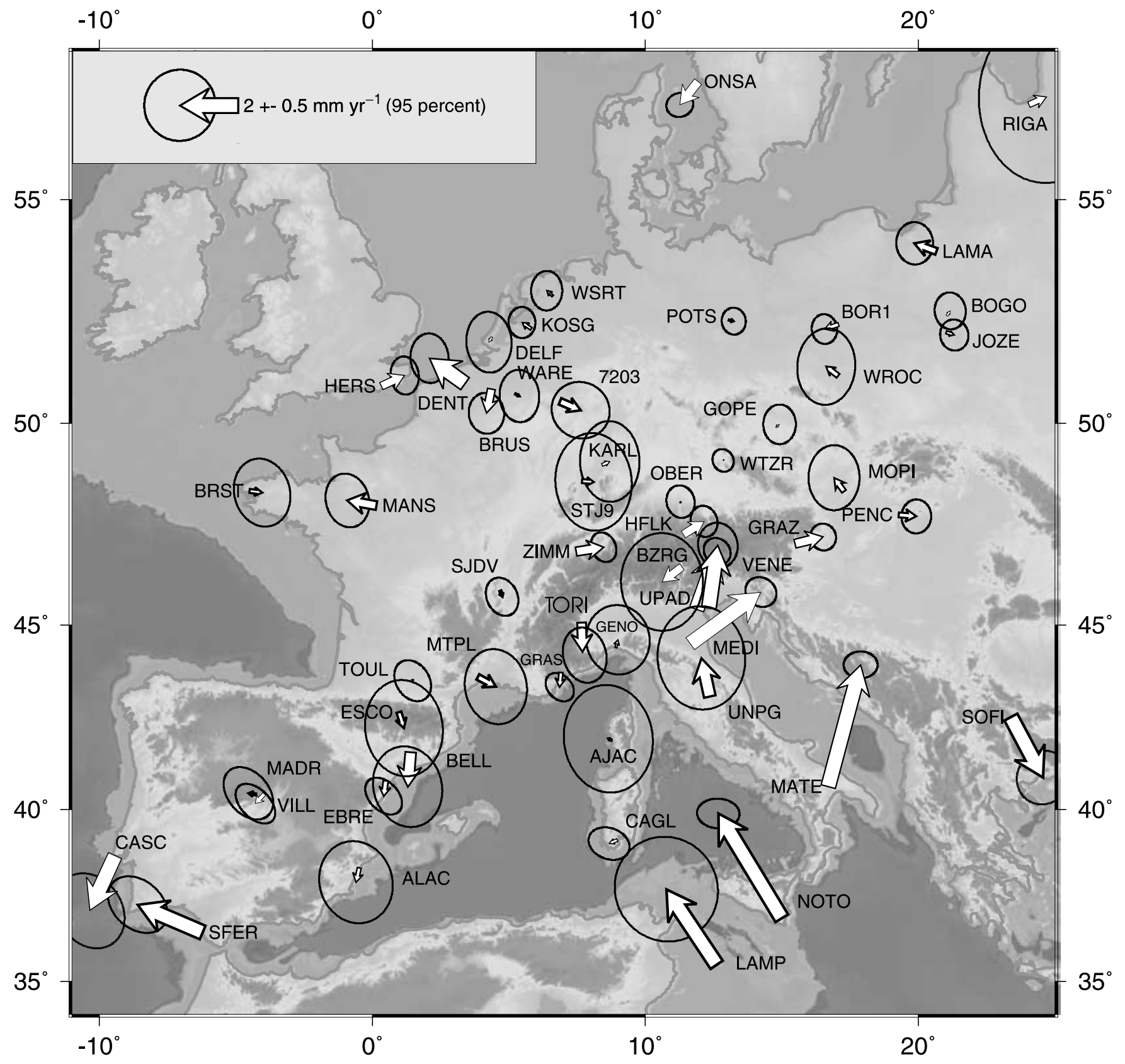

Figure 3. Residual velocities with respect to Central Europe. The Central Europe Reference Frame is defined using BOGO, BOR1, GOPE, JOZE, POTS, WROC, OBER, WSRT, WTZR, RIGA, ZWEN, and 7561. Confidence ellipses (95 per cent confidence level) are computed by adding the variance of the rotation vector defining the reference frame to the variance of the site velocities. Sites located in the Alps are not included in this figure (see Fig. 5). Not included are also GLSV, ZWEN, MDVO, METS, 7561 (see Table 5 for values).

Central Europe at the $0.6 \mathrm{~mm} \mathrm{yr}^{-1}$ level. This result also places an upper bound of $0.6 \mathrm{~mm} \mathrm{yr}^{-1}(1 \sigma)$ on the possible current horizontal motion across the Rhine graben.

The Iberian peninsula is separated from the rest of Europe by the Pyrenees mountains. The Pyrenees have a moderate seismicity with some instrumentally recorded earthquakes reaching magnitude 5 or greater, mostly in the northwestern part of the range (Delouis et al. 1993; Souriau \& Pauchet 1998). Our statistical tests show that the velocities of all the sites on the Iberian peninsula, except SFER, located in the Africa-Eurasia plate boundary zone, have insignificant residual velocities with respect to Central Europe (Table 11). Together with the velocity at site TOUL, located in France about
$100 \mathrm{~km}$ north of the Pyrenees, these results imply an upper bound of the order of $0.6 \mathrm{~mm} \mathrm{yr}^{-1}$ for active motion in the Pyrenees. Consequently, except for its southern part (Betics Cordillera, southern Portugal) that may already belong to the Africa-Eurasia plate boundary zone, the Iberian peninsula can be considered as rigidly attached to Central Europe at the $0.6 \mathrm{~mm} \mathrm{yr}^{-1}$ level $(1 \sigma$ confidence level).

An important result of this study is that we do not confirm Nocquet et al.'s (2001) results that suggested a differential motion of $1-1.5 \mathrm{~mm} \mathrm{yr}^{-1}$ between Central and Western Europe. Given the improved accuracy and consistency of ITRF2000 over ITRF97 and the fact that the solution presented here relies on a combination of 
Table 11. Statistical tests of consistency with the stable Europe subset of sites.

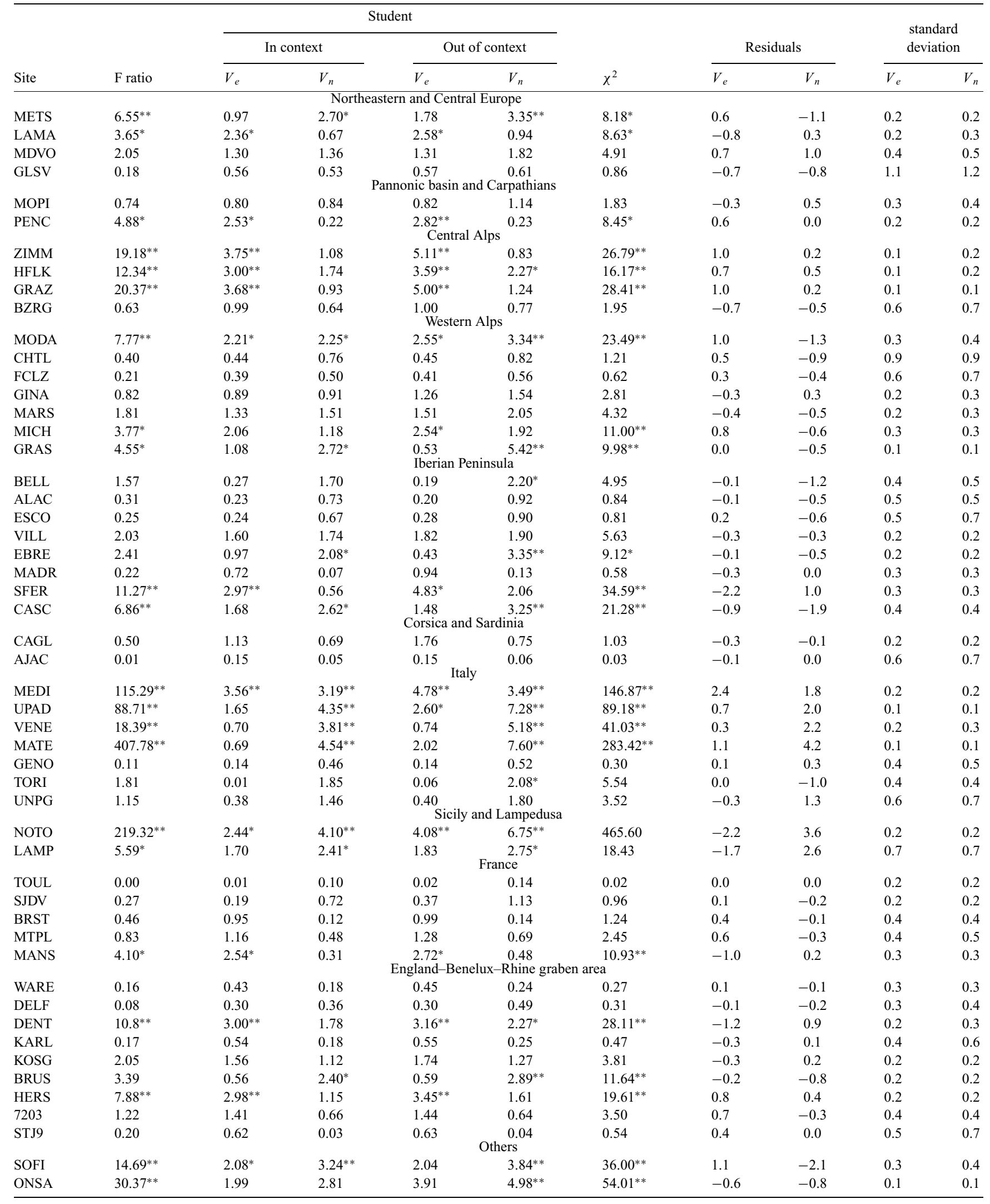

${ }^{*}$ Test fails at a 95 per cent confidence level; ${ }^{* *}$ test fails at a 99 per cent confidence level. 
three additional solutions, we believe that Nocquet et al.'s (2001) analysis for the Eurasian plate interior in Western Europe was incorrect because of a slight bias $\left(1 \mathrm{~mm} \mathrm{yr}^{-1}\right)$ in the ITRF97 data set for Western Europe and a too optimistic interpretation of formal velocity uncertainties.

\subsection{Interplate motion}

\subsubsection{Africa-Eurasia convergence in the Western Mediterranean}

In the Central Europe reference frame defined above, NOTO and LAMP (Lampedusa Island) show a similar northwestward velocity of $4 \mathrm{~mm} \mathrm{yr}^{-1}$, in a direction fairly consistent with the NUVEL1A prediction for the African Plate, but with a magnitude about half of that of the model (Fig. 4). This indicates either that the NUVEL1A Africa-Eurasia relative plate motion values are overestimated, or that NOTO and LAMP do not belong to the rigid African Plate. Indeed, both sites are located within less than $100 \mathrm{~km}$ of active faults of the Africa-Eurasia plate boundary zone (Westaway 1990). In addition, NOTO is located on the Iblean block, which has been interpreted as moving independently from the African and Eurasian plates (Mantovani et al. 1995). Assuming that NUVEL1A does provide the actual Africa-Eurasia plate motion, the residual velocities at NOTO and LAMP with respect to Africa imply 3-4 $\mathrm{mm} \mathrm{yr}^{-1}$ of convergence between them and stable Africa. However, no active compressional structures are known south of LAMP and NOTO. This indicates that the NUVEL1A Africa-Eurasia motion is not consistent with direct geodetic measurements. We went one step further by assuming that the motion of SFER, even though that site is clearly located within the Africa-Eurasia plate boundary zone, may be consistent with that of the African Plate and inverted for a rigid rotation using NOTO, LAMP, SFER (Model 1, Fig. 4, Table 13). We find rotation parameters that fit the data well, with residuals of less than 1 $\mathrm{mm} \mathrm{yr}^{-1}$. In a second step, we add the ITRF2000 velocity of MASP (Maspalomas, Canary Island) to the (NOTO, LAMP, SFER) subset and estimate a new rotation (Model 2, Fig. 4, Table 13). Residuals are now of the order of $1.5 \mathrm{~mm} \mathrm{yr}^{-1}$. These rotation parameters differ significantly from the NUVEL1A values for the African Plate and imply an Africa-Eurasia convergence rate about 50 per cent slower than the NUVEL1A values and rotated $20^{\circ}-30^{\circ}$ counterclockwise (Fig. 4).

Our rotation parameters for the African Plate are derived from four sites only with a poor geometrical coverage. In addition, at least one of them (SFER) is located within the plate boundary zone. Therefore, they may not be representative of the motion of the whole African (or Nubian) plate. However, they are consistent with the Nubia/Eurasia rotation parameters derived from a larger data set by Sella et al. (2002, REVEL model, Table 13). Also, these rotation parameters fit preliminary GPS velocities better than the NUVEL1A model at sites in Morocco south of the Atlas (Reilinger et al. 2001). Our data set is not sufficient to demonstrate that the NUVEL1A Africa-Eurasia rotation parameters does not provide the proper kinematic boundary condition for the Western Mediter-

Table 12. Threshold values for Table 11.

\begin{tabular}{lcc}
\hline Test & 95 per cent & 99 per cent \\
\hline F ratio $(2,23)$ & 3.42 & 5.66 \\
Student $(23)$ & 2.07 & 2.81 \\
$\chi^{2}(2)$ & 5.99 & 9.21 \\
\hline
\end{tabular}

Values in parenthesis are degrees of freedom. ranean. However, our results suggest that a revision of the Africa (Nubia)/Eurasia relative motion, based on an augmented geodetic data set in Africa, is needed.

\subsubsection{The Adriatic microplate}

Sites located on the Italian peninsula show the largest velocity residuals in a Central Europe reference frame. Anderson \& Jackson (1987), using seismological data, had proposed that the Adriatic indenter may actually be an independent microplate, detached from the African Plate and rotating counterclockwise with respect to Eurasia around a pole located at $45.8^{\circ} \mathrm{N} / 10.2^{\circ} \mathrm{E}$. Westaway (1990) used tectonic information and earthquake focal mechanisms to infer a rotation of the Adriatic microplate at $0.3 \mathrm{deg} \mathrm{Ma}^{-1}$ around a pole at $44.5^{\circ} \mathrm{N} / 9.5^{\circ} \mathrm{E}$. Using VLBI results at MATE and MEDI, Ward (1994) reached a similar conclusion but proposed a rotation pole located at $46.8^{\circ} \mathrm{N} / 6.3^{\circ} \mathrm{E}$ and an angular rate of $0.30 \pm 0.06^{\circ} / \mathrm{Ma}$. In the following, we use new geodetic data to estimate the kinematic boundary conditions across the western Alps and test whether they can explain the observed strain regime in the range. However, Mantovani et al. (1995), pointed out that because of its tectonic position on the active northeastward thrusts of the external Apennines, MEDI cannot be used to derive a rigid rotation for the Adriatic block. In addition, station MATE is located south of an active fault zone cutting the Italian peninsula and the Adriatic Sea in an EW direction from Gargano to Dubrovnik. That fault, clearly expressed in the seismicity, was identified by Westaway (1990) as the southern boundary of the Adriatic microplate. We therefore consider that MATE is not part of the Adriatic microplate. We inverted the velocities of TORI and UPAD together with the earthquake slip vector data set used by Anderson \& Jackson (1987) and found a counterclockwise rotation of the Adriatic block with respect to stable Europe around pole located at $45.36^{\circ} \mathrm{N} / 9.10^{\circ} \mathrm{E}$ at an angular rate of $0.52 \mathrm{deg} \mathrm{Ma}^{-1}$ (see Fig. 5, Calais et al. 2002 for details).

Velocities predicted using our rotation parameters with respect to stable Europe along the boundary between the Po plain and the western Alps are oblique to the Adriatic-western Alps boundary, indicating that the current kinematic boundary conditions across the central part of the western Alps combine divergence and rightlateral shear. Extensional boundary conditions are also predicted to prevail across the Swiss Alps. In the southern part of the western Alps, the eastward curvature of the active structures, together with the velocities at GRAS, MARS or AJAC, imply kinematic boundary conditions that combine convergence and right-lateral shear. This model also predicts that kinematic boundary conditions across the Alps east of $9.22^{\circ} \mathrm{E}$ (longitude of the Adriatic-Central Europe rotation pole) should be essentially $\mathrm{N}-\mathrm{S}$ convergence between the Adriatic microplate and Central Europe.

These predictions are consistent with most of the first-order seismotectonic features around the Adriatic microplate, including $\mathrm{N}-$ $\mathrm{S}$ to NW-SE compression in the Friuli area in Italy and further west in the southern part of the Central Alps (Reilly \& Arca 1987; Benedetti et al. 2000), a transition to dextral shear and extension in the Swiss Alps (Eva \& Solarino 1998; Maurer et al. 1997) and the western Alps (Eva \& Solarino 1998; Sue et al. 1999), and NWSE to NS compression in the southern part of the western Alps (Eva \& Solarino 1998; Maddedu et al. 1997). Our model predicts $4 \mathrm{~mm} \mathrm{yr}^{-1}$ of NE-SW extension across the central Apennines, consistent with GPS and triangulation results in that area (Hunstad \& England 1999; D'Agostino et al. 2001). Finally, the motion of MATE relative to the Adriatic microplate (convergence in a $\mathrm{N} 74^{\circ} \mathrm{W}$ 

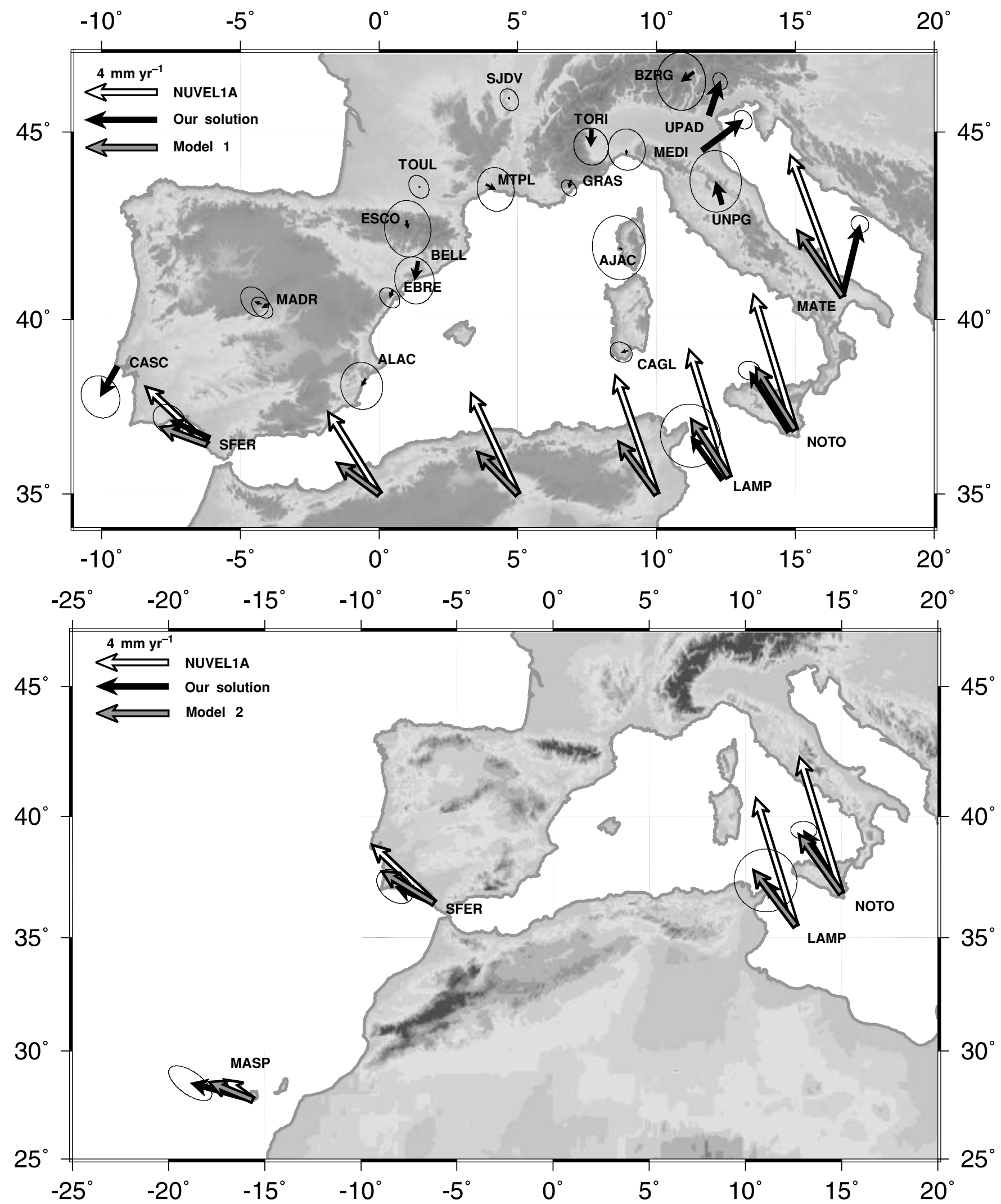

Figure 4. Kinematic boundary condition in Western Mediterranean. Top: comparison between the NUVEL1A Africa-Eurasia velocities (white vectors) and the observed velocities derived from the present study (with respect to Central Europe). Bottom: Comparison between the Africa-Eurasia velocities obtained by estimating rotation parameters from velocities at NOTO, LAMP, SFER, and MASP (white vectors) and the observed velocities derived from the present study (with respect to Central Europe). 
Table 13. Rotation parameters for the Africa-Eurasia relative motion.

\begin{tabular}{lccc}
\hline Model & $\begin{array}{c}\text { latitude } \\
\text { deg }\end{array}$ & $\begin{array}{c}\text { longitude } \\
\text { deg }\end{array}$ & $\begin{array}{c}\text { angular velocity } \\
\text { deg/Myr }\end{array}$ \\
\hline Argus $^{1}$ & 18.8 & -20.3 & $0.10 \pm 0.02$ \\
NUVEL1A $^{2}$ & 21.0 & -20.6 & $0.13 \pm 0.02$ \\
REVEL $^{3}$ & 18.2 & -20.0 & $0.06 \pm 0.005$ \\
Model 1 (NOTO LAMP SFER) & 15.5 & -13.9 & $0.07 \pm 0.01$ \\
Model 2 (NOTO LAMP SFER MASP) & 14.2 & -17.5 & $0.07 \pm 0.01$ \\
\hline
\end{tabular}

${ }^{1}$ Argus et al. (1989), ${ }^{2}$ DeMets et al. (1990), DeMets et al. (1994), ${ }^{3}$ Sella et al. (2002). The REVEL motion for Africa (Nubia) is calculated using GOUG $\left(40.35^{\circ} \mathrm{S}, 350.12^{\circ} \mathrm{E}\right.$, Gough Island, south Atlantic), HARZ and HRAO, $\left(25.89^{\circ} \mathrm{S}, 27.71^{\circ} \mathrm{E}\right.$, Hartebeesthoek, South Africa), MASP $\left(27.76^{\circ} \mathrm{N}, 344.27^{\circ} \mathrm{E}\right.$, Mas Palomas), and SUTH $\left(32.38^{\circ} \mathrm{S}, 20.81^{\circ} \mathrm{E}\right.$, South Africa).

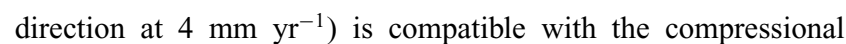
focal mechanisms observed along the Gargano-Dubrovnic fault zone.

In the Eastern Alps and Pannonian basin, we find east to northeastward residual velocities at sites GRAZ $\left(1.2 \pm 0.2 \mathrm{~mm} \mathrm{yr}^{-1}\right)$ and PENC $\left(0.6 \pm 0.2 \mathrm{~mm} \mathrm{yr}^{-1}\right)$, consistent with earlier results from Grenerczy et al. (2000), within their uncertainties.

\section{CONCLUSIONS}

We have proposed a theoretical framework for rigorously combining regional GPS networks and densify larger-scale networks such that the EUREF-EPN or the ITRF2000. Although we only presented results from continuous networks, the combination of campaign solutions is also possible. The resulting velocity field is consistent at a continental scale and includes a realistic assessment of the velocity (and position) errors. In a second step, this velocity field can be used to define a rigid-plate reference frame for mapping velocities for the purpose of a geophysical interpretation of the residuals. A careful selection of the best stations is necessary at both stages in order to ensure a reliable final velocity field.

Using this methodology, we have derived a consistent velocity field for Western Europe by combining daily or weekly solutions from several geodetic networks: the ITRF2000 global solution, the EUREF-EPN solution, a national solution from the French permanent GPS network and a regional solution from a permanent GPS network centred on the western Alps. Intraplate deformation in Europe and fault slip rates in active tectonic structures such as the Rhine graben and the western Alps are close to or below the accuracy of current space geodetic techniques. Consequently, proper constraints handling in geodetic solutions as well as a careful definition of the reference frame are essential for the tectonic interpretation of residual velocities in Europe, and in general when interpreting a velocity field at a continental scale (Dixon et al. 1996; Chen et al. 2000; Shen et al. 2000; Nocquet et al. 2001).

We show that Central Europe (east of the Rhine graben, north of the Alps and Carpathians, south of Fennoscandia) behaves rigidly at the $0.4 \mathrm{~mm} \mathrm{yr}^{-1}$ (wrms) level. We find no significant relative motion between Central and westernmost Europe (at the $0.6 \mathrm{~mm} \mathrm{yr}^{-1}$ level) and no significant strain in Western Europe outside of the actively deforming areas of the Alps and Apennines. Using Central Europe as a reference frame, we find significant residual velocities for sites located on the Adriatic Plate and for sites possibly located on the African Plate. We show that the motion of the Adriatic block is not consistent with that of the African Plate, confirming earlier results of Anderson \& Jackson (1987) and Ward (1994). Its kinematics can be modelled by a counterclockwise rotation with respect to sta- ble Europe. The boundary conditions imposed along the border of the Adriatic block by that rotation are qualitatively consistent with first-order seismotectonic data in the Alps, Apennines and Dinarides. The kinematics of the Adriatic Plate therefore seems to drive deformation in the surrounding areas of the Alps, Apennines, and Dinarides. These results raise the issue of the driving mechanism for the motion of the Adriatic Plate, which does not appear to be related to the African Plate motion in a simple manner. A definite answer to this question is beyond the scope of this study and would require dynamic geophysical models incorporating realistic boundary conditions (Africa-Eurasia plate motion and Aegean subduction, located just east of our study area) and stresses induced by gravitational potential energy variations (e.g. Molnar \& Lyon-Caen 1988) and/or by the peri-Adriatic subducted slabs (Wortel \& Spakman 2001) and by the westward push of the Anatolian-Aegean-Balkan system (Tapponnier 1977; Mantovani et al. 2002).

Our results also suggest that the NUVEL1A global plate model does not accurately describe the Africa-Eurasia convergence in the Western Mediterranean. However, more stations on the African Plate and longer time-series are necessary in order to derive a reliable kinematics for the African Plate from direct geodetic measurements.

Finally, the fact that we do not confirm Nocquet et al.'s (2001) results of a $1-1.5 \mathrm{~mm} \mathrm{yr}^{-1}$ differential motion between Central and Western Europe shows that the geophysical interpretation of velocities at the $1 \mathrm{~mm} \mathrm{yr}^{-1}$ level, especially with widely spaced networks, should be made with caution. The geodetic solution for Europe presented here is a significant improvement over earlier results because it includes longer data time-series and, most importantly, and because of the redundancy introduced by the rigorous combination of independent geodetic solutions, necessary to achieve the best possible accuracy.

\section{ACKNOWLEDGMENTS}

We thank all the individuals and institutions participating in the EUREF-EPN network for making high-quality data publicly available and the analysis centres that contributed their solutions to the EUREF-EPN. We thank P. Nicolon (IGN) for providing us with the weekly RGP solutions and the agencies operating and maintaining the permanent GPS stations of the REGAL network (University of Savoie, IPSN, University of Montpellier, LDG, Géosciences Azur). We are particularly grateful to Z. Altamimi (IGN) for providing the combination software and for his advice in combination procedures. We acknowledge the insightful comments of two anonymous reviewers. This work was funded by the French national programme 'Géofrance 3D' (BRGM, MENR, INSU) and by the ACI 'Catastrophes Naturelles' (MRT). 


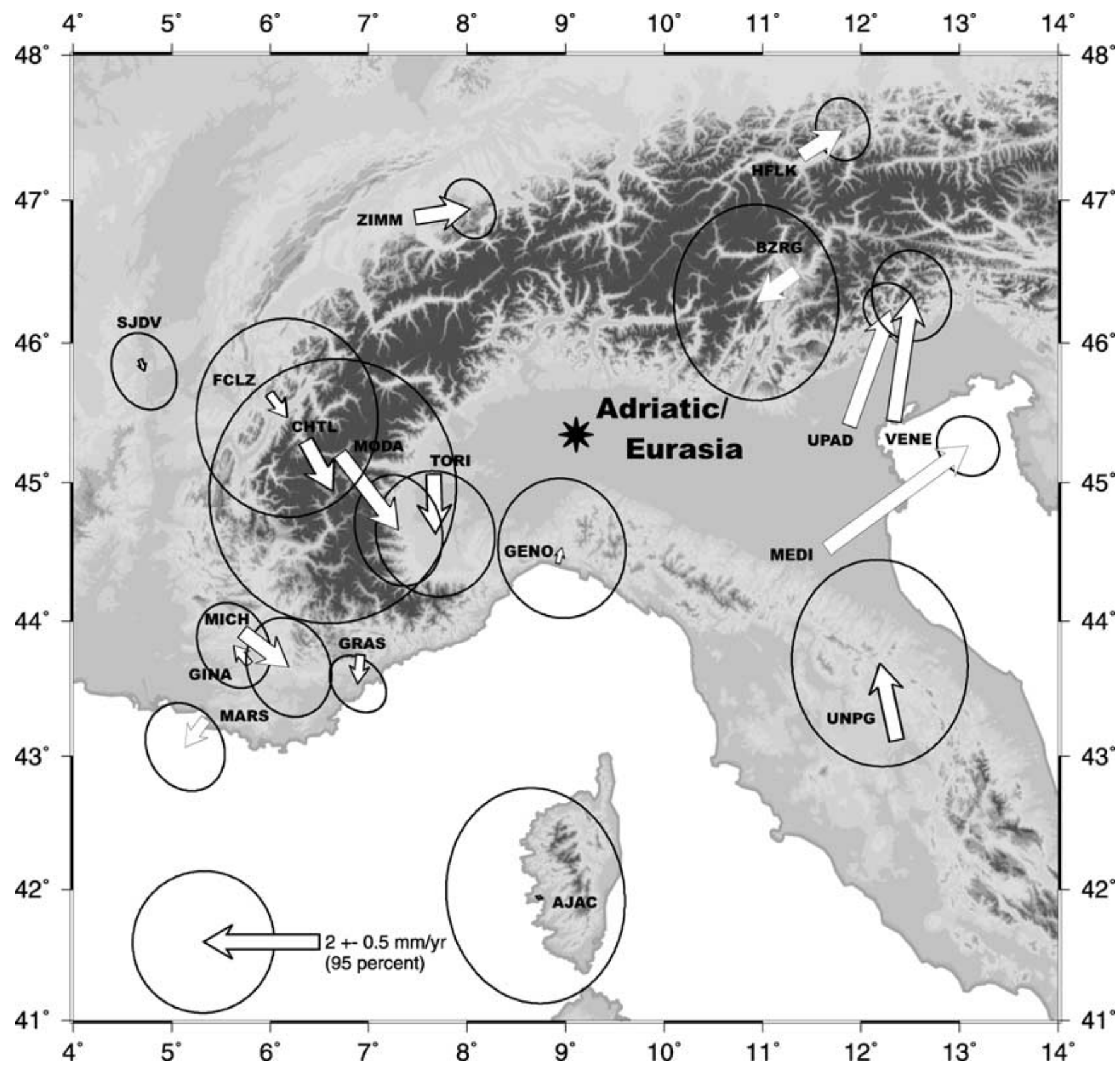

Figure 5. Residual velocities with respect to Central Europe, close-up on the Alps. The Central Europe Reference Frame is defined using BOGO, BOR1, GOPE, JOZE, POTS, WROC, OBER, WSRT, WTZR, RIGA, ZWEN, 7561 to estimate a rigid rotation. Confidence ellipses (shown here at the 95 per cent confidence level) are computed by adding the variance of the rotation vector defining the reference frame to the variance of the site velocities. The star indicates the location of the Adriatic/Eurasia Euler pole computed from UPAD and TORI velocities and earthquake slip vector data used by Anderson \& Jackson (1987).

\section{REFER E N CES}

Altamimi, Z. \& Boucher, C., 2001. The ITRS and ETRS89 relationship: new results from ITRF2000, Proceedings of the EUREF Symposium, Dubrovnik, 16-18 May, 2001.

Altamimi, Z., Sillard, P. \& Boucher, C., 2002. ITRF2000: a new release of the international terrestrial reference frame for Earth science applications, J. geophys. Res., 107, 2214, doi: 10.1029/2001JB000561.

Anderson, H.A. \& Jackson, J.A., 1987. Active tectonics of the Adriatic region, Geophys. J. R. astr. Soc., 91, 937-983, 1987.

Argus, D.F. \& Gordon, R.G., 1991. No-net-rotation model of current plate velocities incorporating plate motion model NUVEL-1, Geophys. Res. Lett., 18, 2039-2042.
Argus, D.F \& Gordon, R.G., 1996. Tests of the rigid-plate hypothesis and bounds on intraplate deformation using geodetic data from the very long baseline interferometry, J. geophys. Res., 101, 13 555-13 572.

Benedetti, L., Tapponnier, P., King, G., Meyer, B. \& Manighetti, I., 2000. Growth folding and active thrusting in the Montello region, Veneto, northern Italy, J. geophys. Res., 105, 739-766.

Beutler, G. et al., 2001. Bernese GPS software version 4.2, Astronomical Institute and University of Berne.

Brockmann, E., 1997. Combination of solutions for geodetic and geodynamics applications of the Global Positionning System, 1996-1998, PhD thesis, University of Bern, 55, 211.

Calais, E. et al., 2000. REGAL: a permanent GPS network in the western Alps: configuration and first results, C.R. Acad. Sci., Ser. II, 331, 435-442. 
Calais, E., Nocquet, J.-M., Jouanne, F. \& Tardy, M., 2002. Current strain regime in the western Alps from continuous GPS measurements, 19962001, Geology, 30, 651-654.

Chen, Z. et al., 2000. Global Positioning System measurements from eastern Tibet and their implications for India/Eurasia intercontinental deformation, J. geophys. Res., 105, 16215-16227.

D’Agostino, N. \& McKenzie, D., 1999. Convective support of longwavelength topography in the Apennines (Italy), Terra Nova, 11, 234-238.

D’Agostino, N., Giuliani, R., Mattone, M. \& Bonci, L., 2001. Active crustal extension in the central Apennines (Italy) inferred from GPS measurements in the interval 1994-1999:, Geophys. Res. Lett., 28, 21212124.

Davies, P. \& Blewitt, G., 2000. Methodology for global geodetic time series estimation: a new tool for geodynamics, journal, J. geophys. Res., 105, $11083-11100$.

Delouis, B., Haessler, H., Cisternas, A. \& Rivera, L., 1993. Stress tensor determination in France and neighbouring regions, Tectonophysics, 221, 413-438.

DeMets, C., Gordon, R.G., Argus, D.F. \& Stein, S., 1990. Current plate motions, Geophys. J. Int. 101, 425-478.

DeMets, C., Gordon, R.G., Argus, D.F. \& Stein, S., 1994. Effect of recent revisions to the geomagnetic reversal time scale on estimates of current plate motions, Geophys. Res. Lett., 21, 2191-2194.

Dixon, T.H., Mao, A. \& Stein, S., 1996. How rigid is the stable interior of the North American plate?, Geophys. Res. Lett., 23, 3035-3038.

Eva, E. \& Solarino, S., 1998. Variations of stress directions in the western Alpine Arc, Geophys. J. Int. 135, 438-448.

Grenerczy, G., Kenyeres, A. \& Fejes, I., 2000. Present crustal movement and strain distribution in Central Europe inferred from GPS measurements, $J$. geophys. Res., 105, 21 835-21846.

Herring, T.A., Davis, J.L. \& Shapiro, I.I., 1990. Geodesy by Radio Interferometry: the application of Kalman filtering to the analysis of very long baseline interferometry data, J. geophys. Res., 95, 12 561-12 581.

Hunstad, I. \& England, P., 1999. An upper bound on the rate of strain in the central Apennines from triangulation measurements between 1869 and 1963, Earth planet. Sci. Lett., 169, 261-267.

Johansson, J.M. et al., 2002. Continuous GPS measurements of postglacial adjustment in Fennoscandia, 1. geodetic results, J. geophys. Res., 107, 0148-0227, doi: 10.1029/2001JB000400.

King, R.W. \& Bock, Y., 2001. Documentation for the GAMIT GPS software analysis, release 10.05, MIT, Cambridge.

Lemeille, F., Cushing, M., Cotton, F., Grellet, B., Menillet, F., Audru, J.C., Renardy, F. \& Fléhoc, C., 1999. Evidence for middle to late Pleistocene faulting within the northern Upper Rhine Graben (Alsace Plain, France), C.R. Acad. Sci. II, 328, 839-846.

Maddedu, B., Béthoux, N. \& Stéphan, J.F., 1997. Champ de contrainte postpliocène et déformations récentes dans les Alpes sud-occidentales, Bull. Soc. Géol. Fr., 167, 797-810.

Mantovani, E., Alabarello, D., Tamburelli, C. \& Viti, M., 1995. Tectonic interpretation of large scale geodetic measurements (VLBI, SLR) in the central Mediterranean region: constraints and uncertainties, Ann. Geofis., 38, 67-84.

Mantovani, E., Viti, M., Albarello, D., Tamburelli, C., Babbucci, D. \& Cenni, N., 2000. Role of kinematically induced forces in Mediterranean tectonics: insights from numerical modeling, J. Geodyn., 30, 287-320.

Mantovani, E., Albarello, D., Babbucci, D., Tamburelli, C. \& Viti, M., 2002. Trench arc-back arc systems in the Mediterranean area: examples of extrusion tectonics, in Reconstruction of the Evolution of the Alpine-Himalayan
Orogeny, Journal of the Virtual Explorer. http://www.virtualexplorer. com.au

Marotta, A.M. \& Sabadini, R., 2002. Tectonic versus glacial isostatique adjustment in Europe, Geophys. Res. Lett., 29, 0094-8276, doi: 10.1029/ $2001 \mathrm{GL} 013865$.

Maurer, H., Burkhard, M., Deichmann, N. \& Green, G., 1997. Active tectonism in the Central Alps: contrasting stress regimes north and south of the Rhone Valley, Terra Nova, 9, 91-94.

Milne, G.A., Davis, J.L., Mitrovica, J.X., Scherneck, H.-G., Johansson, J.M., Vermeer, M. \& Koivula, H., 2001. Space-geodetic constraints on glacial isostatic adjustment in Fennoscandia, Science, 291, 2381-2385.

Molnar, P. \& Lyon-Caen, H., 1988. Some simple physical aspects of the support, structure \& evolution of mountain belts, Spec. Pap. Geol. Soc. Amer., 218, 179-297.

Morel, J.L. \& Meghraoui, M., 1996. The Goringe-Alboran-Tell (GALTEL) tectonic zone, a transpression system along the Africa-Eurasia plate boundary, Geology, 24, 755-758.

Nicolas, M., Santoire, J.P. \& Delpech, P.Y., 1990. Intraplate seismicity: new seismotectonic data in Western Europe, Tectonophysics, 179, 27-53.

Nocquet, J.M., Calais, E., Altamimi, Z., Sillard, P. \& Boucher, C., 2001. Intraplate deformation in Western Europe deduced from an analysis of the ITRF-97 velocity field, J. geophys. Res., 106, 11 239-11258.

Peltier, W.R., 1995. VLBI baseline variations from the ICE-4G model of post-glacial rebound, Geophys. Res. Lett., 22, 465-468.

Reilinger, R., McClusky, S., Ben Sari, D., Mourabit, T. \& Gomez, F., Barazangi, M., 2001. Preliminary evidence of active deformation in Morocco from repeat GPS observations, AGU 82(47), Fall Meet. Suppl., Abstract. AGU, Washington, DC.

Reilly, W.I. \& Arca, S., 1987. Crustal strain in Friuli, 1949-1977, Boll. Geod. Sci. Affini, 46, 247-254.

Reilly, W.I. \& Gubler, E., 1990. Crustal strain in Switzerland 1870-1970, Geophys. J. Int. 103, 251-256.

Sella, G.F., Dixon, T.H. \& Mao, A., 2002. REVEL: a model for recent plate velocities from space geodesy, J. geophys. Res., 107, 0148-0227, doi: 10.1029/2000JB000033.

Shen, Z., Zhao, C., Yin, A., Li, Y., Jackson, D.D., Fang, P. \& Dong, D., 2000. Contemporary crustal deformation in east Asia constrained by Global Positioning System measurements, J. geophys. Res., 105, 5721-5734.

Sillard, P. \& Boucher, C., 2001. A review of algebraic constraints in terrestrial reference frame datum definition, J. Geodesy, 75, 63-73.

Souriau, A. \& Pauchet, H., 1998. A new synthesis of the Pyrenean seismicity and its tectonic implications, Tectonophysics, 290, 221-244.

Sue, C., Thouvenot, F., Fréchet, J. \& Tricart, P., 1999. Widespread extension in the core of the western Alps revealed by earthquake analysis, J. geophys. Res., 104, 25 611-25622.

Tapponnier, P., 1977. Evolution tectonique du système alpin en Méditerranée: poinçonnement et écrasement rigide-plastique., Bull. Soc. Géol. Fr., 19, 437-460.

Vigny, C. et al., 2002. GPS network monitors the western Alps: deformation over a five-year period: 1993-1998, J. Geodesy, 76, 63-76.

Ward, S.N., 1994. Constraints on the seismotectonics of the central Mediterranean from very long baseline interferometry, Geophys. J. Int. 117, 441452 .

Westaway, R., 1990. The Tripoli, Libya, earthquake of September 4, 1974: implications for the active tectonics of the central Mediterranean, Tectonics, 9, 231-248.

Wortel, R. \& Spakman, W., 2001. Subduction and Slab detachment in the Mediterranean-Carpathian region, Science, 290, 1910-1917. 